\title{
Ice Thermal Energy Storage (ITES) for air-conditioning application in full and partial load operating modes
}

\author{
Sepehr Sanaye* Mohammad Hekmatian \\ Energy systems improvement laboratory (ESIL) \\ School of Mechanical Engineering \\ Iran University of Science and Technology (IUST)
}

\begin{abstract}
One method for reducing electricity consumption in an air-conditioning (AC) system is using ice thermal energy storage (ITES) system. ITES systems are divided into two categories, full and partial operating modes (FOM and POM). In this study, an AC with ITES system is first modeled and analyzed in energy, exergy, economic and environmental (4E) aspects in two full and partial load operating modes. Multi-objective optimization technique and Genetic Algorithm were used for computing the optimum values of design parameters. Exergy efficiency and total annual cost were considered as two objective functions in multi-objective optimization. The comparison of ITES system in full and partial operating modes with that for traditional system showed reduction in electricity consumption (11.83\% for FOM and $10.23 \%$ for POM) due to the fact that ITES system produced just as much as cooling load was required. Additionally switching electricity consumption from on-peak to off-peak hours caused a reduction in electricity consumption cost (32.65\% for FOM and $13.45 \%$ for POM).

Keywords: Ice thermal energy storage (ITES), Air-condition, Full and Partial operating mode
\end{abstract}

\footnotetext{
* Corresponding author: Sepehr Sanaye, Energy Systems Improvement Laboratory, School of Mechanical Engineering, Iran University of Science and Technology, Narmak, Tehran, Iran, 16844, Tel-Fax:+98-2177240192

E-mail address: sepehr@iust.ac.ir
} 


\section{Nomenclature:}

\begin{tabular}{|c|c|}
\hline A & Heat transfer surface area $\left(m^{2}\right)$ \\
\hline$C_{\text {elec }}$ & Electricity cost $\left(\$ k W h^{-1}\right)$ \\
\hline $\mathrm{COP}$ & Coefficient of performance \\
\hline$C_{p}$ & Specific heat at constant pressure $\left(k J k g^{-1} K^{-1}\right)$ \\
\hline $\mathrm{CRF}$ & Capital recovery factor \\
\hline CTES & Cold thermal energy storage \\
\hline $\mathrm{E}$ & $\operatorname{Exergy}(k W h)$ \\
\hline$\dot{E}$ & Exergy flow rate $(k W)$ \\
\hline Elc & Annual electricity consumption \\
\hline $\mathrm{F}$ & Logarithmic mean temperature difference correction factor \\
\hline FOM & Full Operating Mode \\
\hline $\mathrm{h}$ & Specific enthalpy $\left(k J k g^{-1}\right)$ \\
\hline $\mathrm{i}$ & Interest rate $(\%)$ \\
\hline$i_{p h}$ & Melting latent heat $\left(\mathrm{kJkg}^{-1}\right)$ \\
\hline ITES & Ice thermal energy storage \\
\hline $\mathrm{k}$ & Specific heat rate \\
\hline $\mathrm{m}$ & $\operatorname{mass}(k g)$ \\
\hline$\dot{m}$ & Mass flow rate $\left(\mathrm{kgs}^{-1}\right)$ \\
\hline $\mathrm{N}$ & Operational hours in a year \\
\hline $\mathrm{n}$ & System life time \\
\hline NTU & Number of transfer unit \\
\hline
\end{tabular}




\begin{tabular}{|c|c|}
\hline $\mathrm{P}$ & Pressure $\left(p_{a}\right)$, extra cost payback period (year) \\
\hline POM & Partial Operating Mode \\
\hline$\dot{Q}$ & The time rate of heat transfer $(k W)$ \\
\hline$Q_{c}$ & Cooling load $(k W h)$ \\
\hline$\dot{Q}_{c}$ & Cooling load rate $(k W)$ \\
\hline$R_{t h}$ & Total thermal resistance $\left(m^{2} K k W^{-1}\right)$ \\
\hline $\mathrm{s}$ & Specific entropy $\left(k J k^{-1} K^{-1}\right)$ \\
\hline $\mathrm{T}$ & Temperature $(K)\left({ }^{o} C\right)$ \\
\hline $\mathrm{U}$ & Overall heat transfer coefficient $\left(k W m^{-2} K^{-1}\right)$ \\
\hline $\mathrm{u}$ & Specific internal energy $\left(\mathrm{kJkg}^{-1}\right)$ \\
\hline $\mathrm{V}$ & $\operatorname{Volume}\left(m^{3}\right)$ \\
\hline VCR & Vapor Compression Refrigeration \\
\hline$\dot{V}$ & Volumetric flow rate $\left(m^{3} s^{-1}\right)$ \\
\hline$\dot{W}$ & The time rate of energy transfer by work $(k W)$ \\
\hline $\mathrm{Z}$ & Capital cost $(\$)$ \\
\hline$\dot{Z}$ & Annual Capital cost $\left(\frac{\$}{\text { year }}\right)$ \\
\hline
\end{tabular}

\section{Greek symbols}

$\eta \quad$ Isentropic efficiency 


$\begin{array}{ll}\mu_{\mathrm{CO}_{2}} & \mathrm{CO}_{2} \text { emission factor }\left(\mathrm{kg} \mathrm{WWh}^{-1}\right) \\ v & \text { Specific volume }\left(\mathrm{m}^{3} \mathrm{~kg}^{-1}\right) \\ \rho & \text { Density }\left(\mathrm{kgm}^{-3}\right) \\ \Phi & \text { Maintenance factor } \\ \varphi & \text { Relative factor } \\ \psi & \text { Exergy efficiency } \\ \omega & \text { Absolute humidity (kg water vapor } \mathrm{kg}^{-1} \text { dry air) }\end{array}$

\section{Subscripts}

\begin{tabular}{ll} 
a & Air \\
amb & Air handling unit \\
C & Ambient \\
CH & Cooling load \\
ch & chemical \\
Comp & Charging \\
Cond & compressor \\
CT & Condenser \\
cv & Cooling tower \\
CW & Control volume \\
D & Chilled water \\
dc & destruction \\
EV & Discharging \\
\hline
\end{tabular}




\begin{tabular}{|c|c|}
\hline EX & Expansion valve \\
\hline $\mathrm{f}$ & Final \\
\hline FP & Freezing point \\
\hline $\mathrm{g}$ & gas \\
\hline $\mathrm{i}$ & inlet \\
\hline int & Initial \\
\hline inv & Investment \\
\hline 1 & Leakage \\
\hline LMTD & Logarithmic Mean Temperature Difference \\
\hline main & Maintenance \\
\hline o & Outlet \\
\hline op & Operation \\
\hline $\mathrm{PH}$ & Physical \\
\hline $\mathrm{r}$ & Refrigerant \\
\hline ST & Storage tank \\
\hline suc & Suction \\
\hline sv & Salvage value \\
\hline $\mathrm{T}$ & Time \\
\hline TAC & Total Annual Cost \\
\hline tot & Total \\
\hline w & Water \\
\hline WB & Wet-bulb \\
\hline
\end{tabular}




\section{1-Introduction}

Air-conditions (AC) are among the most common energy consuming equipment in residential, administrative, commercial and industrial buildings in various countries specially those in tropical regions. About 60 percent of total electricity consumption is related to AC systems (Habeebollah, 2007). Different methods have been used for reducing the energy consumption of $\mathrm{AC}$ equipment and its corresponding costs in buildings. These methods are divided into two active and passive categories. Shading of facades and fenestrations, use of thermal insulation material, proper orientation of building envelop which are used during building construction are among passive methods while Cold Thermal Energy Storage (CTES) is an active one. CTES transfers the peak of electricity consumption from on-peak hours to off-peak hours. The medium fluid can be chilled water, ice or eutectic salts. Numerous studies have been carried out by various researchers in the field of CTES systems. Saito (2002) reviewed results regarding CTES operating conditions and compared advantages and disadvantages of various types of CTES. Rosen and Dincer (2003) investigated the performance of thermal energy storage systems (including aquifer systems, stratified storages, and CTES systems) from exergy point of view and estimated their optimal discharge period for each TES method. West and Braun (2004) presented two models for investigating a CTES system performance in partial operating mode. The mathematical modeling and optimization of a chilled water thermal storage system was performed by Henze et al. (2008). They considered the capital cost as the objective function and showed that addition of ITES systems to conventional cooling systems is cost-effective. Bi et.al (2010) minimized exergy destruction and entropy production in a CTES system. 
Among various CTES systems, ITES systems are more common due to lower costs and using smaller storage tanks (Rismanchi, 2012). Dincer (2002) studied design, optimization and operation of an ITES. Chen et al, (2005) studied and modeled an ITES system and estimated the amount of stored ice and heat transfer rate for charging ITES by a vapor compression refrigeration (VCR) system (with R-22 refrigerant). MacPhee and Dincer (2009) evaluated the performance of four major types of ice storage techniques based on energy and exergy analyses in charging and discharging processes. The results showed that energy analysis alone cannot give realistic information of the system behavior, and that is why exergy analysis of the system is essential. Sanaye and Shirazi (2012) investigated an ITES system by 3E (energy, exergy and economic) modeling and analysis. The total cost rate (including investment, operating, maintenance costs as well as cost of exergy destruction) was the objective function in that study. Sanaye and Shirazi (2013) also modeled an ITES system and carried out a 4E (energy, exergy, economic and environmental) analyses on ITES system in FOM. In their study, they optimized the system using two objective functions (total cost rate and exergy efficiency).

ITES systems operate in two full and partial operating modes. In full operating mode (FOM), all cooling load required during on-peak period, would be produced by a VCR system of ITES during off-peak hours (charging period), and VCR is off during the onpeak period (discharging period). In partial operating mode (POM) VCR would operate with nominal load constantly during on and off peak hours (Dincer, 2002). Habeebullah (2007) performed economic analysis of full and partial operating modes (FOM and POM) for cooling system ka'ba the holy shrine of God. He showed that full operating mode system for the above case study (the holy shrine of God) was more economical. 
Using ITES systems and their auxiliary equipment incur extra initial costs in comparison with that for conventional systems. However additional costs are paid back in a short time not only due to reduction of electricity consumption, but also due to lower cost for shifting electricity consumption from on-peak hours to off peak hours.

This study focuses on comparison of FOM and POM in optimum ITES design. After 4E (energy, exergy, economic and environmental) analysis, multi-objective optimization of ITES in FOM and POM were performed. ITES system included charging cycle, discharging cycle and an energy storage tank. Total annual cost (including initial investment costs, maintenance costs, operating costs and $\mathrm{CO}_{2}$ production penalty costs) was minimized and exergy efficiency was maximized as two objective functions in this study.

Briefly the main subjects discussed in this study are as follows:

- An ITES system (including all sub-systems and equipment) was modeled in full and partial operating modes (FOM and POM) for an office building and analyzed from energy, exergy, economic and environmental points of view.

- The optimum values for the system design parameters in full and partial operating modes were obtained by Genetic Algorithm multi-objective optimization. Two objective functions included total annual cost (which should be minimized) and exergy efficiency (which should be maximized).

- The electricity consumptions and $\mathrm{CO}_{2}$ production of ITES system for full and partial operating modes as well as the same results for a conventional system were compared and results were reported. 
The procedure of analysis and optimization of FOM and POM for an ITES as well as comparison of equipment difference and energy consumption of these systems with that for conventional cooling system are innovations of the present paper.

\section{2- ITES system modeling}

In this study, ITES system is modeled for an AC system in full (Fig.1) and partial (Fig.2) operating modes. An ITES system is composed of charging discharging cycles.

Charging cycle (VCR system) includes compressor, condenser, evaporator, cooling tower, expansion valve while discharging cycle includes air handling unit (AHU), discharging pump, and storage tank. Refrigerant R134a and water-Glycol mixture are used as working fluids in charging cycle (VCR) and discharging cycles respectively.

At FOM (Fig.1), VCR is used for producing chilled water or ice in storage tank during off-peak hours at which the electricity cost is low (the charging cycle). During on-peak hours with increased electricity cost VCR system is off and the water passes through pipes which are placed inside the ice storage tank and the produced chilled water then flows through AHU unit to provide the required cooling load of the building (discharging cycle).

At POM, during on-peak hours VCR system is running with the same constant cooling capacity as off-peak hours (however, the cooling capacity of FOM-ITES is bigger than that for POM-ITES).

\section{2-1-Energy analysis}

Energy analysis of ITES full and partial operating modes are studied in this section. In order to simplify the modeling of the ITES system, the following assumptions are considered: 
- Expansion valve heat loss was taken to be negligible.

- It was assumed that the produced cooling energy was stored in the medium (water/ice) in storage tank.

- States of refrigerant exiting the evaporator and the condenser were assumed to be saturated vapor and saturated liquid, respectively.

- Steady state and uniform temperature distribution were assumed for the storage tank.

\section{2-1-1-Cooling load in ITES full and partial operating modes}

\section{FOM}

In full operating mode the cooling load required for the building $\left(Q_{C}\right)$ as is shown in

Fig. 3 is estimated as follows:

$Q_{C}=\int_{t_{d c}} \dot{Q}_{c}(t) d t$

In which $t_{d c}$ is the discharging time of the system. The air mass flow rate passing through the AHU is computed from $\mathrm{Eq}(2)$ :

$\dot{m}_{a}=\frac{\dot{Q}_{C}}{h_{1}-h_{2}}$

Where for the moist air the enthalpy difference $\left(h_{1}-h_{2}\right)$ is computed for dry air (the first term) and water vapor (the second term) in $\operatorname{Eq}(3)$ :

$h_{1}-h_{2}=\left(C_{p, a} T_{1}+\omega_{1} h g_{1}\right)-\left(C_{p, a} T_{2}+\omega_{2} h g_{2}\right)$

The absolute humidity of the air used in equation (3) is expressed as follows:

$$
\omega=0.622 \times \frac{\varphi \times p_{w s}}{p_{a t m}-\varphi \times p_{w s}}
$$


In which $p_{w s}$ is water vapor saturation pressure at the ambient dry bulb temperature which is function of ambient temperature and $\varphi$ is the relative humidity of the air, respectively. Due to existing heat loss from storage tank a thermal efficiency $\left(\eta_{S T}\right)$ was defined. Furthermore it was assumed that the storage tank had equal diameter and height to have the minimum heat transfer with the surroundings [Macphee and Dincer (2004)]. The total value of the stored cooling load in the tank was computed from the following Eqs:

$Q_{S T}=\frac{Q_{C}}{\eta_{S T}}$

$\eta_{S T}=\frac{Q_{S T}-Q_{l, c h}-Q_{l, d c}}{Q_{S T}}=1-\left(\frac{Q_{l, c h}+Q_{l, d c}}{Q_{S T}}\right)$

In equation (6) $Q_{l, c h}$ and $Q_{l, d c}$ express the amount of heat leakage from the tank in charging and discharging cycles, respectively. The values of $Q_{l, c h}$ and $Q_{l, d c}$ were estimated in the next section.

\section{POM}

For partial operating mode as illustrated in Fig.3, the required cooling load can be expressed in the following form:

$Q_{C}=\int_{t_{d c}+t_{c h}} \dot{Q}_{c}(t) d t=\dot{Q}_{C} \times 24$

Providing the required building cooling load in partial operating mode (POM), was performed by pumping chilled water from storage tank to AHU.

At POM, VCR is producing chilled water or ice in storage tank with constant cooling capacity all day long. 


\section{2-1-2-charging cycle for ITES full and partial operating modes}

\section{FOM}

For full operating mode of ITES in charging process, VCR was used to produce chilled water or ice in the storage tank. If one assumes that the total value of the stored cooling in the tank $\left(Q_{S T}\right)$ is known, then the evaporator heat transfer rate can be estimated as:

$\dot{Q}_{E V}=\frac{Q_{S T}}{t_{c h}}$

In which $t_{c h}$ shows the period of producing chilled water or ice in storage tank (charging period) by VCR system. Therefore, according to equation (9), the refrigerant mass flow rate in VCR system can be expressed as:

$$
\dot{m}_{r}=\frac{\dot{Q}_{E V}}{h_{6}-h_{5}}
$$

Assuming that $\dot{m}_{r}$ is known, the compressor power consumption can be estimated as:

$\dot{W}_{\text {comp }}=\dot{m}_{r}\left(h_{7}-h_{6}\right)$

Furthermore compressor isentropic efficiency $\eta_{\text {comp }}$ is defined by:

$$
\eta_{\text {comp }}=\frac{h_{7 s}-h_{6}}{h_{7}-h_{6}}
$$

Or by an equivalent expression (Kotas, 1995):

$$
\eta_{\text {comp }}=0.85-0.46667\left(\frac{p_{7}}{p_{6}}\right)
$$

Heat rejection from condenser was also estimated from $\mathrm{Eq}(13)$ :

$$
\dot{Q}_{\text {cond }}=\dot{m}_{r}\left(h_{7}-h_{8}\right)
$$


Based on the value of $\dot{Q}_{\text {cond }}$, the mass flow rate of water in cooling tower was estimated by (ASHRAE, 2008):

$\dot{m}_{c T}=43.2 \times 10^{-3} \dot{Q}_{c o n d}$

Finally by definition of VCR coefficient of performance (COP) is:

$C O P=\frac{\dot{Q}_{E V}}{\dot{W}_{c o m p}}$

By estimating the heat transfer surface area of evaporator and condenser from Eq (16) (Kakac and Liu, 2002):

$$
A=\frac{N T U \times\left(\dot{m}_{c p}\right)_{\min }}{U}
$$

The amount of power consumption required for cooling tower pump can be computed from Eq (17) (Kakac and Liu, 2002):

$\dot{W}_{\text {pump }, c t}=\frac{\dot{m}_{c T} \times \Delta P_{i}}{\rho_{w} \times \eta_{p u m p}}$

In which $\Delta P_{i}$ and $\eta_{\text {comp }}$ represent the cooling tower water side pressure drop and the isentropic efficiency of the pump, respectively.

The electricity consumed by the cooling tower fan $\left(\dot{w}_{f a n, C T}\right)$ was also estimated from Eq (18) (Cengel et al, 2006):

$$
\dot{W}_{f a n, C T}=\frac{\Delta p_{a} \times \dot{V}_{a}}{\eta_{f a n} \eta_{m}}
$$

In which $\Delta p_{a}, \dot{V_{a}}, \eta_{f a n}$ and $\eta_{m}$ represent the cooling tower air side pressure drop, air volume flow rate isentropic efficiency and mechanical efficiency of the fan, respectively. 
By assuming uniform temperature distribution inside the storage tank (with mixed ice and water), the heat leakage from the storage tank would be function of inlet chilled water temperature into the tank, surrounding temperature, storage tank heat transfer surface area and thermal resistance during the charging process. If uniform temperature storage tank at the end of charging process is $\mathrm{T}_{\mathrm{ST}}$, the amount of heat leaked from the storage tank during the charging cycle $\left(Q_{l, c h}\right)$ can be computed by the following relation:

$Q_{l, c h}=A_{S T} \frac{T_{a m b}-T_{S T}}{R_{t h}} t_{c h}$

In which $A_{S T}, R_{t h}$ and $t_{c h}$ represent the storage tank heat transfer surface area, thermal resistance of the storage tank and the time of the charging cycle. $\mathrm{A}_{\mathrm{ST}}$ is estimated from Eq (20) proposed by (Kilkis and Kakac, 1989; Macphee and Dincer, 2009):

$V_{S T}=\frac{3600 Q_{S T}}{\rho_{w} C_{p, w}\left(T_{d c}-T_{F P, w}\right)+\rho_{w} i_{p h}+\rho_{i c e} C_{p, i c e}\left(T_{F P, w}-T_{S T}\right)}$

$A_{S T}=6 \pi\left(\frac{V_{S T}}{2 \pi}\right)^{2 / 3}$

$Q_{l, c h}$ is constant during a month due to constant average ambient temperature but changes during a year for each month due to change in average ambient monthly temperature .

\section{POM}

For partial operating mode during charging cycle, VCR system was used for producing chilled water or ice in the storage tank all day long with constant cooling power. As $Q_{C}$ is the total cooling load required for the building, the heat transfer rate from the evaporator could be computed as follows: 
$\dot{Q}_{E V}=\frac{Q_{S T}}{24}$

In partial operating mode, VCR system is continuously working at nominal capacity for supplying the cooling load for producing chilled water or ice in storage tank during both on and off peak hours at 24 hours a day.

It is obvious that the numerical value of $\dot{m}_{r}$ in partial operating mode is smaller than that for the full operating mode due to selected smaller VCR system.

\section{2-1-3-Discharging cycle of ITES full and partial operating modes}

\section{FOM}

In discharging cycle, the pump sends the chilled water passing through pipes located inside the ice storage tank toward AHU unit to provide the required cooling load for the building. In this state, the total heat transfer coefficient, heat transfer surface area and the air pressure drop inside AHU can be computed using relations presented by (Sanaye et al., 2011).

The power consumption of fan in the AHU ( $\left.\dot{w}_{f a n, A H U}\right)$ in Fig.1, is also computed by the following relation (Kakac and Liu, 2002):

$\dot{W}_{f a n, A H U}=\frac{\left(\Delta p_{0}+\Delta p_{f a n}\right) \times \dot{V}_{a}}{\eta_{f a n} \cdot \eta_{m}}$

In which $\Delta P_{o}, \Delta P_{f a n}, \dot{V_{a}}$ and $\eta_{f a n}$ represent the AHU air side pressure drop, the fan pressure drop, the air volume flow rate and the isentropic efficiency of the fan, respectively.

The power consumption of chilled water pump in discharging case $\left(\dot{w}_{\text {pump, }, d c}\right)$ in Fig.1 is obtained by the following relation (Kakac and Liu, 2002): 
$\dot{w}_{\text {pump }, d c}=\frac{\dot{m}_{c w} \times \Delta P_{i}}{\rho_{c w} \times \eta_{\text {pump }}}$

In which $\dot{m}_{c w}, \Delta P_{i}$, and $\eta_{\text {pump }}$ represent chilled water mass flow rate, chilled water pressure drop inside AHU coil and isentropic efficiency of the pump, respectively.

The rate of heat transfer leakage in the storage tank during the discharge cycle is obtained by the following relation:

$Q_{l, d c}=A_{S T} \frac{T_{a m b}-T_{d c}}{R_{t h}} t_{d c}$

In which $T_{d c}$ and $t_{d c}$ represent the temperature of storage tank (with mixed ice and water) and the discharge process duration time, respectively.

\section{POM}

For partial operating mode the relations for $\dot{w}_{f a n, d c}$ and $Q_{l, d c}$ are used just the same as Eqs (23) and (25). $\dot{m}_{c w}$ and $A_{S T}$ in this case represent chilled water mass flow rate in the storage tank and area of the storage tank respectively, which are smaller than those for full operating mode.

\section{2-2-Exergy analysis of ITES full and partial operating modes}

\section{FOM}

From steady state, steady flow analysis of the exergy change rate in a control volume (Cengel et al, 1998):

$$
\frac{d E_{c . v}}{d t}=\sum_{j} \dot{E}_{j} Q-\dot{E}_{j}^{w}+\sum_{i} \dot{E}_{i}-\sum_{e} \dot{E}_{e}-\dot{E}_{D}=0
$$

In which $\dot{E}_{i}$ and $\dot{E}_{e}$ represent the exergy transfer rate in a control volume at the inlet and outlet respectively, $\dot{E}_{D}$ represents the exergy destruction rate due to irreversibilities in 
a control volume, and $\dot{E}^{w}$ and $\dot{E}^{Q}$ represent exergy transfer rate due to work and heat transfer from control volume boundaries respectively.

In absence of electromagnetic effects, static electricity, nuclear forces and surface tension effects and also assuming negligible change of kinetic and potential energy, one can divide exergy flow rate in a system into physical and chemical types (Kotas, 1995):

$\dot{E}=\dot{E}^{p h}+\dot{E}^{c h}$

For an ITES system without chemical reactions, chemical exergy ( $\dot{E}^{c h}$ ) would be omitted. Therefore we have:

$\dot{E}=\dot{E}^{p h}=\dot{m}\left[\left(h-h_{O}\right)-T_{O}\left(s-s_{O}\right)\right]$

where index (0) stands for dead state ( system in atmospheric temperature $\left(T_{0}\right)$ and $\left.\operatorname{pressure}\left(P_{0}\right)\right)$.

For liquids (incompressible fluids), $\dot{E}$ would be:

$\dot{E}=\dot{m} c_{p} T_{O}\left[\frac{T}{T_{O}}-1-\operatorname{Ln}\left(\frac{T}{T_{0}}\right)\right]$

While for an ideal gas $\dot{E}$ would be:

$\dot{E}=\dot{m} c_{p} T_{O}\left[\frac{T}{T_{O}}-1-\operatorname{Ln}\left(\frac{T}{T_{O}}\right)+\frac{k-1}{k} \operatorname{Ln}\left(\frac{p}{p_{O}}\right)\right]$

Furthermore the total rate of exergy destruction is:

$\dot{E}_{D, t o t}=\dot{E}_{D, A H U}+\dot{E}_{D, c o m p}+\dot{E}_{D, E X}+\dot{E}_{D, c o n d+c T}+\dot{E}_{D, E V}+\dot{E}_{D, S T}$

in which for each equipment we have:

$\dot{E}_{D, A H U}=\left(\dot{E}_{1}+\dot{E}_{3}\right)-\left(\dot{E}_{2}+\dot{E}_{4}\right)$ 


$$
\begin{aligned}
& \dot{E}_{D, \text { comp }}=\left(\dot{E}_{6}-\dot{E}_{7}\right)+\dot{W}_{\text {comp }} \\
& \dot{E}_{D, E X}=\dot{E}_{8}-\dot{E}_{5} \\
& \dot{E}_{D, \text { cond }+c T}=\left(\dot{E}_{7}+\dot{E}_{10}\right)-\left(\dot{E}_{8}+\dot{E}_{9}\right) \\
& \dot{E}_{D, E V}=\left(\dot{E}_{5}-\dot{E}_{6}\right)+\dot{E}_{E V} Q
\end{aligned}
$$

In the above relations $\dot{E}_{E V}^{Q}$ represents exergy transfer rate due to heat transfer from the evaporator of the chiller obtained as follows:

$$
\dot{E}_{E V} Q=\dot{Q}_{E V}\left(1-\frac{T_{O}}{T_{E V}}\right)
$$

Exergy destruction rate in the ice storage tank $\left(\dot{E}_{D, S T}\right)$ includes exergy destruction during charging cycle $\left(\dot{E}_{D, c h}\right)$ and exergy destruction during discharging cycle $\left(\dot{E}_{D, d c}\right)$ expressed as follows:

$$
\dot{E}_{D, S T}=\dot{E}_{D, c h}+\dot{E}_{D, d c}
$$

In the above equation, for charging cycle, the exergy destruction ( $\left.\dot{E}_{D, c h}\right)$ is:

$$
\dot{E}_{D, c h}=\frac{E_{D, c h}}{t_{c h}}=\frac{E_{S T, c h}^{Q}-\left(E_{f}-E_{i}\right)_{S T, c h}}{t_{c h}}
$$

In which exergy in the storage tank during charging cycle equals to:

$$
E_{S T, c h}^{Q}=\left(Q_{l, c h}-Q_{S T}\right)\left(1-\frac{T_{O}}{T_{S T}}\right)
$$

Where $Q_{S T}$ is the heat transfer rate between the VCR refrigerant (inside tubes) and water or water-ice or ice inside storage tank during charging period. Then from multiplying terms in the first parenthesis to the second one, exergy destruction due to storage tank 
cooling loss and exergy destruction due to cooling gain from VCR system were obtained respectively.

During the charging cycle, at the initial state of storage tank (i), there was water with $T_{d c}$ temperature inside the tank, while in the final state (f) the tank contained ice with $T_{S T}$ temperature (assuming uniform temperature distribution inside the storage tank). Therefore $T_{d c}$ (initial state of water in storage tank) was bigger than $T_{F P}$ (the water freezing point), and $T_{S T}$ (the final state of storage tank with full ice) was lower than $T_{F P}$ $(\mathrm{Eq} 41)$ :

$T_{S T}<T_{F P}<T_{d c} \quad T_{F P} \approx-0.1^{\circ} \mathrm{C} \quad$ and $\quad-10^{\circ} \mathrm{C}<T_{S T}<-0.1^{\circ} \mathrm{C}$

As the specific entropy change during phase change is (Cengel et al, 2011):

$$
\left(s_{\text {solid phase }}-s_{\text {liquid phase }}\right)=C_{p, \text { liquid phase }} \operatorname{Ln}\left(\frac{T_{\text {Freezing point }}}{T_{d c}}\right)-\frac{i_{\text {phase change }}}{T_{\text {Frezzing point }}}+C_{p, \text { solid phase }} \operatorname{Ln}\left(\frac{T_{\text {solid phase }}}{T_{\text {Freezing point }}}\right)
$$

The total exergy change of storage tank during charging cycle, $\left(E_{f}-E_{i}\right)_{S T, c h}$ was estimated as (Sanaye and Shirazi, 2013):

$$
\begin{aligned}
& \left(E_{f}-E_{i}\right)_{S T, c h}=m_{w, S T}\left[\left(u_{f}-u_{i}\right)-T_{O}\left(s_{f}-s_{i}\right)\right]_{S T, c h} \\
& =\left(Q_{l, c h}-Q_{S T}\right)-m_{w, S T} T_{O}\left[C_{p, w} \operatorname{Ln}\left(\frac{T_{F P, w}}{T_{d c}}\right)-\frac{i_{p h}}{T_{F P, w}}+C_{p, i c e} \operatorname{Ln}\left(\frac{T_{S T}}{T_{F P, w}}\right)\right]
\end{aligned}
$$

The first term inside the last bracket represents the specific entropy change inside the storage tank for the process of changing water with $T_{d c}$ temperature to water with $T_{F P, W}$ temperature $\left(s_{f}-s_{i}\right)$. The second term represents the specific entropy change due the 
phase change of water into ice (solidification entropy change). The third term represents the process of changing the ice temperature from $T_{F P, W}$ to $T_{S T}$.

Similarly for discharging cycle, the exergy destruction was estimated from:

$$
\dot{E}_{D, d c}=\dot{E}_{D, \text { melting,dc }}+\dot{E}_{D, C W, d c}
$$

In which $\dot{E}_{D, \text { melting, } d c}$ represents exergy destruction rate due to ice melting in the storage tank. $\dot{E}_{D, C W, d c}$ also represents exergy destruction rate due to heat transfer between water-ice in storage tank and the chilled water inside tubes. Therefore by applying Eq (26) $\dot{E}_{D, \text { melting,dc }}$ is expressed as:

$\dot{E}_{D, \text { melting, } d c}=\frac{E_{D, \text { melting }, d c}}{t_{d c}}=\frac{E_{S T, d c}^{Q}-\left(E_{f}-E_{i}\right)_{S T, d c}}{t_{d c}}$

where indexes (i) and (f) denote initial state of ice at temperature $T_{S T}$ and final state of water at temperature $T_{d c}$ for the ice storage tank. $E_{S T, d c}^{Q}$ and $\left(E_{f}-E_{i}\right)_{S T, d c}$ are estimated from Eqs (46) and (47) respectively:

$$
\begin{aligned}
& E_{S T, d c}^{Q}=\left(Q_{l, d c}+Q_{c}\right)\left(1-\frac{T_{0}}{T_{d c}}\right) \\
& \left(E_{f}-E_{i}\right)_{S T, d c}=m_{w, S T}\left[\left(u_{f}-u_{i}\right)-T_{0}\left(s_{f}-s_{i}\right)\right]_{S T, d c} \\
& =\left(Q_{l, d c}+Q_{c}\right)-m_{w, S T} T_{0}\left[C_{p, w} \operatorname{Ln}\left(\frac{T_{d c}}{T_{F P, w}}\right)+\frac{i_{p h}}{T_{F P, w}}+C_{p, i c e} L n\left(\frac{T_{F P, w}}{T_{S T}}\right)\right]
\end{aligned}
$$

where $Q_{c}$ is the heat transfer between the chilled water feeding to AHU and ice or icewater or water in storage tank during discharging period. Other terms inside the bracket are the same as those described in equation 43 . 
In addition, $\dot{E}_{D, C W, d c}$ (in Eq.44), the exergy destruction due to changing ice from $T_{F P, W}$ temperature to water with $T_{d c}$ temperature was obtained from relation (26):

$\dot{E}_{D, C W}=\left(\dot{E}_{4}-\dot{E}_{3}\right)+\dot{E}_{C W} Q$

Finally, the total exergy efficiency for the whole ITES system was defined as:

$\Psi_{t o t}=\frac{\dot{E}_{\text {out }}}{\dot{E}_{\text {in }}}=1-\left(\frac{\dot{E}_{D, t o t}}{\dot{W}_{f a n, A H U}+\dot{W}_{\text {pump }, d c}+\dot{W}_{\text {cond }}+\dot{W}_{\text {pump }, c T}+\dot{W}_{f a n, c T}}\right)$

where $\dot{E}_{D, t o t}$ is introduced in equation 31 .

\section{POM}

For partial operating mode, the basic exergy rate balance equations are the same as those for the full operating mode except for the lower values of refrigerant mass flow rate $\dot{m}_{r}$ and cooling duty (Fig3), in partial operating mode, in comparison with that for FOM. The latter case was occurred due to the fact that in POM the VCR system was running during both on-peak and off-peak periods.

\section{2-3- Economic analysis}

Generally, total annual cost for an ITES system included capital or investment cost of whole ITES system, maintenance cost, operational cost and also penalty cost due to carbon dioxide production in atmosphere. Therefore, we can express the total annual cost (TAC) as:

$T A C=\dot{Z}_{i n v+\text { main }}+\dot{Z}_{o p}+\dot{Z}_{\mathrm{Co}_{2}, \text { penalty }}$ 


\section{2-3-1- investment and maintenance costs for full and partial operating modes}

\section{FOM}

Investment costs (\$) for equipment in ITES system $\left(Z_{k}\right)$ are listed in table (1). The annualized investment cost (\$/year) and annual maintenance cost (\$/year) can be also expressed as follows (Humpherys and Kattell,1981):

$\dot{Z}_{k}=Z_{k} \times C R F \times \varphi$

In which CRF and $\varphi$ represent Capital Recovery Factor and maintenance factor respectively. CRF depends on two parameters: i (interest rate) and $\mathrm{n}$ (equipment life time) and can be expressed as follows:

$C R F=\frac{i(1+i)^{n}}{(1+i)^{n}-1}$

Therefore the annualized investment cost for various ITES equipment was estimated from $\mathrm{Eq}(53)$ :

$\dot{Z}_{i n v+\text { main }}=\sum_{k} \dot{Z}_{k}=\dot{Z}_{A H U}+\dot{Z}_{\text {pump }, d c}+\dot{Z}_{S T}+\dot{Z}_{E V}+\dot{Z}_{c o m p}+\dot{Z}_{E X}+\dot{Z}_{c o n d}+\dot{Z}_{c T}+\dot{Z}_{\text {pump }, c T}$

\section{POM}

For partial operating system the required cooling load for the building was provided by pumping chilled water through storage tank. Therefore a smaller storage tank (than that for the full operating mode) was required for supplying the specified cooling load, which means lower investment and maintenance costs for storage tank for POM state. Furthermore a smaller VCR system was needed to supply the required cooling load in this operating mode. 


\section{2-3-2- Operational costs for full and partial load}

\section{FOM}

During the charging cycle, operating costs included VCR compressor power consumption as well as cooling tower pump and fan power consumptions during off-peak period. However in discharging cycle, operating costs included AHU fan power consumption and the chilled water pumping power consumption which sends the chilled water to AHU during on-peak period. Generally, we can express annual operational costs for an ITES system in full operating mode as follows:

$\dot{Z}_{\text {op }}=\left[\left(\dot{w}_{\text {comp }}+\dot{w}_{\text {pump }, c T}+\dot{w}_{\text {fan }, c T}\right) \times C_{\text {elec, off_peak }}\right]+$ $\left[\left(\dot{w}_{\text {pump }, d c}+\dot{w}_{\text {fan }, A H U}\right) \times C_{\text {elec }, \text { on_peak }}\right]$

In which, $C_{\text {elec,on-peak }}$ and $C_{\text {elec,off -peak }}$ represent the unit cost of electricity consumption during on-peak and off-peak periods $\left(\frac{\$}{k W h}\right)$, respectively.

\section{POM}

Operational costs of ITES system in partial operating mode include charging and discharging cycle costs. Operational costs in charging cycle during off-peak hours included costs of electricity consumption for cooling tower pump and fan as well as electricity consumption of VCR compressor. Operational costs during discharge cycle (for on-peak hours) included all terms mentioned for off-peak hours plus electricity consumption by pumping chilled water to AHU as well as electricity consumption of AHU fan. Thus the total annual operational costs in partial operating mode can be expressed as: 
$\dot{Z}_{\text {op }}=\left[\left[\left(\dot{w}_{\text {comp }}+\dot{w}_{\text {pump }, c T}+\dot{w}_{\text {fan }, c T}\right) \times C_{\text {elec,off_peak }}\right]+\right.$

$\left[\left(\dot{w}_{\text {comp }}+\dot{w}_{\text {pump }, c T}+\dot{w}_{\text {fan }, c T}\right) \times C_{\text {elec,on_peak }}\right]+$

$\left.\left[\left(\dot{w}_{\text {pump }, d c}+\dot{w}_{\text {fan }, A H U}\right) \times C_{\text {elec,on_peak }}\right]\right]$

In which $C_{\text {elec,on_peak }}$ and $C_{\text {elec,off _ peak }}$ represent the unit electricity consumption cost during on-peak and off-peak periods, respectively.

Eq (55) in comparison with Eq (54) has an extra term for running VCR system all day long. However due to smaller VCR capacity in partial operating mode, the operational costs for off-peak hours are much lower for POM in comparison with that for FOM.

\section{2-3-3- Estimating payback period}

Using an ITES system either in full or partial operating mode would increase the initial or capital costs due to adding a storage tank however, the additional costs would be compensated by lowering electricity consumption and its corresponding cost, by using the storage tank in on-peak hours. For estimating the payback period due to using new VCR, system, and a storage tank in full and partial operating modes of ITES which are more expensive than the traditional (chiller) system, the following relations were used (Humpherys and Kattell,1981):

$-\Delta\left(\sum_{k} Z_{k}\right)_{F O M}-\Delta\left(Z_{o p-F O M}\right)\left(\frac{(1+i)^{p}-1}{i(1+i)^{p}}\right)+\Delta Z_{s v}\left(\frac{1}{(1+i)^{p}}\right)=0$

Also for POM:

$-\Delta\left(\sum_{k} Z_{k}\right)_{P O M}-\Delta\left(Z_{o p-P O M}\right)\left(\frac{(1+i)^{p}-1}{i(1+i)^{p}}\right)+\Delta Z_{s v}\left(\frac{1}{(1+i)^{p}}\right)=0$ 
Term $\Delta\left(\sum_{k} Z_{k}\right)$ represents the added initial capital costs relative to that for a conventional system in full and partial operating modes, respectively. Also $\Delta Z_{o p}$ represents operational costs saved annually (due to lower operational costs of ITES in comparison with that for conventional system). In equations (56) and (57) $\Delta Z_{s v}$ represents the salvage values of an ITES system in full and partial operating modes in comparison with that for conventional system. Salvage value is defined as the estimated value that an asset will realize upon its sale at the end of its useful life. Finally, "i" and "p" represent the interest rate and payback period.

Equations (56) and (57) are not linear in terms of 'p' and were solved numerically by using Newton-Rophson iterative method.

\section{2-4- Environmental analysis for full and partial operating modes}

The amount of released $\mathrm{CO}_{2}$ for generating electricity for using in an ITES system was a major designing factor and can be estimated from following equation (Wang et al, 2010):

$C O_{2, \text { emission }}[\mathrm{kg}]=\mu_{\mathrm{co}_{2}}\left[\mathrm{~kg} . \mathrm{kWh} h^{-1}\right] \times \operatorname{Elc}_{\text {ann }}[\mathrm{kWh}]$

In which $\mu_{\mathrm{CO}_{2}}$ represents the emission conversion factor of released $\mathrm{CO}_{2}$ for generating electricity and $E l c_{a n n}$ denoted the annual electricity consumption. According to Wang et al (2010) studies, the value of this parameter is considered to be $0.968 \mathrm{kgkWh}^{-1}$. The penalty cost due to the released $\mathrm{CO}_{2}$ is taken $90 \$ /$ ton (IPCC, 2007).. Therefore, the annual penalty cost due to the released $\mathrm{CO}_{2}\left(Z_{\mathrm{Co}_{2}}\right.$,\$/year) can be expressed as follows:

$\mathrm{Z}_{\mathrm{Co}_{2}}=\left(\frac{\mathrm{CO}_{2, \text { emission }}}{1000}\right) \times \mathrm{CO}_{2, \text { emission, penalty }}$ 


\section{3-System optimization}

\section{3-1- The objective function and decision variables}

In this paper, objective functions are exergy efficiency $\left(\Psi_{t o t}, E q .49\right)$ which should be maximized) and total annual cost (TAC, Eq.50) which should be minimized. Design variables in our optimization problem are:

1-The chilled water temperature at AHU inlet $\left(T_{i n, A H U}\right)$

2- The chilled water temperature at AHU outlet $\left(T_{o u t, A H U}\right)$

3-The average temperature of mixed water and ice inside storage tank which is assumed to be uniform throughout the tank $\left(T_{S T}\right)$

4-The Saturation temperature of the refrigerant in evaporator of VCR system ( $\left.T_{E V}\right)$

5 -The condensing temperature in condenser of VCR system ( $\left.T_{\text {cond }}\right)$

A list of design variables for both full and partial operating modes and also their recommended intervals are presented in table (2).

\section{3-2- Genetic Algorithm technique for multi-objective optimization}

Multi objective optimization is a realistic method for solving a vast majority of complex optimization engineering problems. However, objective functions are in contrast with each other in many problems (minimizing the costs while maximizing the performance). Therefore, single-objectively optimizing without taking into consideration the effect of other objective functions, may not give realistic results.

Unlike a single-objective optimization solution, the optimum solution in multi-objective optimization is as a curve named "Pareto front". This curve includes all possible 
solutions and one should select a final point as the optimum solution using decision making methods. Generally, multi-objective optimization can be expressed as follows:

find $x=\left(x_{i}\right) \quad \forall i=1,2,3,4,5 \ldots \ldots \ldots . ., N_{\text {par }}$

maximize or minimize $f_{i}(x) \quad \forall i=1,2,3,4,5 \ldots \ldots \ldots ., N_{o b j}$

$g_{j}(x)=0 \quad \forall j=1,2,3,4,5 \ldots \ldots \ldots . ., m$

$h_{k}(x) \leq 0 \quad \forall k=1,2,3,4,5 \ldots \ldots \ldots, n$

In which $\mathrm{x}, N_{\text {par }}, f_{i}(x), N_{o b j}, g_{j}(x)$ and $h_{k}(x)$ represent the vector of design parameters, number of design parameters, objective functions, number of objectives function and equal and unequal constrain respectively. In this paper, multi-objective Genetic Algorithm technique was used for optimizing objective functions listed in equations (49) and (51).

\section{4- Case study}

The presented model and the above-mentioned optimization technique are used for optimizing an ITES system in an office building in city of Bushehr located in south of Iran. This building is used at administrative hours between 7AM and 7PM. Daily required cooling load for the building is shown in Fig.4. The building cooling load could either provided by a conventional system (with capability of increasing or decreasing for $25 \%$ nominal cooling load) or alternatively by an ITES system in full and partial operating modes.

Fig.5 shows the monthly average of maximum ambient temperature in city of Bushehr in an annual period (IRIMO, 2006). Tables (3) gives a good estimate for the amount of stored cooling inside storage tank in full and partial operating modes for charging and discharging cycles. These tables also present the required building load as well as provided load by a conventional system shown in Fig.4. 
In full operating mode (FOM), during off-peak hours (charging process) building cooling load was stored in the storage tank. During the day, the VCR is off, and the water and ice in storage tank provided the building required cooling load (discharging process).

In partial operating mode (POM), storage tank provided the building required cooling load (discharging process).

$\mathrm{R}-134 \mathrm{a}$ was considered as the refrigerant in VCR system. The Thermal resistance $\left(R_{t h}\right)$ of the storage tank walls was taken as $1980 \frac{\mathrm{m}^{2} . K}{\mathrm{~kW}}$ for both full and partial operating modes (Rosen et al, 2000). The inside building comfort temperature was assumed to be $21{ }^{\circ} \mathrm{C}$ and the comfort relative humidity of air was assumed to be $55 \%$ (ASHRAE 2008). The isentropic efficiency of pumps and fans were assumed to be 0.83 and 0.8 respectively. The ambient pressure was taken to be $1 \mathrm{~atm}$ due to the location of city of Bushehr in southern coasts of the country. The price of domestic electricity consumption during on-peak hours was $0.09 \$$ and during off-peak hours was $0.06 \$$ per $k W h^{-1}$ unit (GIP, 2014 ).

In order to compute CRF mentioned in equation (54), the annual interest rate, useful lifetime of the system and maintenance factor were 15\% (ICB, 2013), 15 years, and 1.06 of total costs of initial investment, respectively. The salvage value $\left(\Delta Z_{s v}\right)$ in Eqs.58 and 59 was considered to be $10 \%$ of the difference between the capital costs of ITES systems (FOM and POM) and conventional system (MII, 2011).

For full operating mode the ITES charging hours were during 12PM-7AM and discharging hours during 7AM-7PM. Therefore for FOM, N, the annual operating hours in months with warm weather (April to December, Fig.4), was 1890 hours 
$(7$ hours $\times 30$ days $\times 9$ months $)$ for charging and 3240 (12hours $\times 30$ days $\times 9$ months $)$ for discharging cycles. Also, for partial operating mode, the charging hours were during all day long and discharging hours were during 7AM-7PM. Therefore for POM, N was 6480 $(24$ hours $\times 30$ days $\times 9$ months $)$ for charging hours and $3240(12$ hours $\times 30$ days $\times 9$ months $)$ for discharging hours.

\section{5- Results and discussion}

\section{5-1- model verification}

The basic parameters of the presented model in this paper, such as refrigerant mass flow

rate $\left(\dot{m}_{r e f}\right)$, compressor power consumption $\left(\dot{W}_{\text {comp }}\right)$ and coefficient of performance (COP) were obtained from the modeling results for ITES in both full and partial operating modes and were compared with the corresponding values reported by reference (Dincer, 2003) to ensure the accuracy of modeling. The difference between two groups of results was less than $1.25 \%$ in this comparison (as presented in table 4).

\section{5-2- optimization results}

In this section, the acquired results from maximizing the exergy efficiency (the first objective function) and minimizing the total cost (the second objective function) and also the optimum values of five design parameters are presented for ITES full and partial operating modes (table 2).

Genetic Algorithm (GA) optimization was applied for 500 generation. Using a search population size of 200 individuals, gene mutation probability of 0.1 . The transferred elites to the next generation were considered equal to 4 . The weight factor for each 
objective function was taken to be 0.5. Migration forward factor and cross over probability factor are considered equal to 0.1 and 0.9 respectively.

All of the above-mentioned values have presented the best results during 100 different runs. Figures (6) and (7) illustrate Pareto-front curve acquired for multi-objective optimized solution for full and partial operating modes, respectively.

\section{Full operating mode (FOM)}

Fig. 6 shows the conflict between two objective functions such that increase in one objective function resulted in a decrease of the other one. As Fig.6 shows, the highest exergy efficiency is at point A $(39.73 \%)$ which corresponds to the highest annual cost ( $1.538 \times 10^{5} \$$ / year $)$. On the other hand, point $\mathrm{B}$ corresponds to the lowest exergy efficiency (32.11\%) which also corresponds to the lowest annual cost ( $1.291 \times 10^{5} \$ /$ year $)$. Therefore, if we take exergy efficiency as the sole objective function, the optimum value would be point $\mathrm{A}$, but if we take rate of cost as the sole objective function, the optimum value would be point B.

\section{Partial operating mode (POM)}

Similarly from Fig.7 it was found that the highest exergy efficiency corresponds to point A $(41.18 \%)$ which also corresponds to the highest annual cost $\left(1.283 \times 10^{5} \$ /\right.$ year $)$. On the other hand, point B corresponds to the lowest exergy efficiency $(31.12 \%)$ which also corresponds to the lowest annual cost $\left(1.051 \times 10^{5} \$ /\right.$ year $)$. Therefore, if exergy efficiency was the sole objective function, the optimum point would be point $\mathrm{A}$, and if the sole objective function was the annual cost, the optimum point would be point B. 


\section{5-3- Method of selection of optimum point in full and partial operating modes}

In this paper, after Euclidian non-dimensionalization of objective functions (Sayyaadi and Mehrabipour, 2012), LINAMP (Liner Programming Technique for multidimensional analysis of Preference) method was chosen due to significant reduction of costs and negligible difference between exergy efficiency in this method in comparison with that for other methods. In LINAMP method the final optimum point was selected from Pareto front with the lowest specific distance from the ideal point (the ideal point is defined as a point at which both of the objective functions reach their best values without considering the interaction effects on each other, Srinirasan and Shocker, 1973). For both ITES full and partial operating modes, the ideal point, non-ideal point and the point with the lowest distance from the ideal point (selected by LINAMP method) are shown in Figs.8 and 9.

Optimum values of design parameters acquired by LINAMP selection method are presented in table (5). Also comparison of computed values of system operating parameters of VCR system for FOM and POM are presented in table (6).

\section{5-4- Comparing optimum values of exergy efficiency and total annual cost at full and partial operating modes}

The optimum values of exergy efficiency for FOM and POM were $36.71 \%$ and $37.19 \%$ respectively. The acquired results of exergy destruction are presented in Fig.10 for full and partial operating modes 
Also, the economic results at the optimum design point for full and partial operating modes are shown in table (7). The total annual cost is bigger for FOM ( $1.291 \times 10^{5}$ \$ year $)$ in comparison with that for POM $\left(1.148 \times 10^{5} \$ /\right.$ year $)$.

\section{5-5-Comparing operating cost and payback periods for FOM and POM}

The first reason of using ITES is that an ITES system (both FOM and POM) consumes less electricity in comparison with that for conventional system due to fact that a conventional system (an electrical chiller) produces more cooling load in comparison with that for an ITES system, as shown in Fig. (4). It should be noted that most of conventional systems which are available in our market are capable of changing the load in steps of $25 \%$ of nominal cooling load and they don't follow the load profile continuously. Therefore the amount of cooling load produced by a conventional system is more than that for ITES system (both FOM and POM). This fact causes to increase the operating cost of a conventional system in comparison with that for ITES. It should be mentioned that lower electricity cost has been achieved for ITES even while the evaporator temperature in ITES (VCR to produce ice) was lower than that for conventional system (a VCR to produce chilled water). Results showed that $11.83 \%$ and $10.23 \%$ reductions in power consumption of traditional system were achieved for ITES with FOM and POM, respectively (Fig.11). Cost analysis showed that the reduction in electricity consumption cost (i.e., annual operational cost) in comparison with that for traditional system were 3254 \$ (11.42\%) and 3159 \$ (11.08\%) for FOM and POM respectively.

The second and main reason of using an ITES system is to shift electricity consumption

from on-peak hours at which electricity has the highest cost $\left(0.09 \frac{\$}{\mathrm{kWh}}\right)$ to off-peak hours 
at which the electricity price has the lowest cost $\left(0.06 \frac{\$}{\mathrm{kWh}}\right)$. Cost analysis showed that reduction in annual operational cost in comparison with that for traditional system for the above second reason were $9341 \$(32.65 \%)$ and $3847 \$(13.45 \%)$ for FOM and POM, respectively.

Furthermore the lower electricity consumption of ITES in comparison with that for conventional system caused to produce less amount of $\mathrm{CO}_{2}$ (for generating electricity).

Results showed that the annual decrease of $\mathrm{CO}_{2}$ production for the required electricity consumption by an ITES in comparison with that for conventional VCR system was $0.605 \times 10^{+6} \mathrm{~kg} /$ year and $0.587 \times 10^{+6} \mathrm{~kg} /$ year for FOM and POM, respectively.

Finally, payback period of additional costs( first term in equations 57 and 58), for an ITES in comparison with conventional VCR system were 3.17 and 3.84 years for POM and FOM systems, respectively. The payback period is longer for FOM because a much smaller storage tank and VCR system were required for POM in comparison with that for FOM.

\section{5-6- Comparison of investment cost and saving for an ITES during system lifetime}

It is obvious that the investment cost for a traditional cooling system (electrical VCR system) is lower $\left(0.965 \times 10^{5} \$\right)$ than that for an ITES for both POM and FOM. Furthermore the investment cost for FOM is bigger than that for POM (table 7), due to higher capacity of VCR system. However, results reveal that the amount of saving in operating cost during the system life time (15 years) were $1.735 \times 10^{5} \$$ for the FOM and 
$0.899 \times 10^{5} \$ M \$$ for POM, which shows that saving is higher for ITES at FOM operating mode.

\section{6- Conclusions}

An ITES (including equipment for charging and discharging cycles) for an $\mathrm{AC}$ application at full and partial operating mode was modeled and analyzed in energy, exergy, economic and environment (4E) aspects. The system was then optimized using GA multi-objective optimization by defining exergy efficiency and total annual cost (including investment costs, maintenance costs, operational costs and also penalty costs due to $\mathrm{CO}_{2}$ release for generation of electricity consumption by the system) as objective functions.

The maximum exergy efficiency of $36.71 \%$ and $37.19 \%$ for full and partial operating modes were obtained. The minimum total annual cost $1.291 \times 10^{5}$ \$ / year and $1.051 \times 10^{5} \$ /$ year for full and partial costs were also obtained, respectively. Results for our case study showed a reduction of $11.83 \%$ and $10.23 \%$ in electrical power consumption which corresponded to reduction of 3254 \$ $(11.42 \%), 3159$ \$ $(11.08 \%)$ annual operating cost in full and partial operating modes, respectively in comparison with that for conventional system. Also operational costs decreased 32.65\% (9341\$) and $13.45 \%$ (3848 \$) for full and partial operating modes respectively, due to transferring the electricity consumption for providing cooling load from on-peak hours to off-peak hours. Furthermore, lower electricity consumption of ITES in comparison with that for conventional system, is equivalent to produce less amount of $\mathrm{CO}_{2}$ for generating electricity. Results showed that the annual decrease of $\mathrm{CO}_{2}$ production for lower need to 
electricity consumption by ITES is $0.605 \times 10^{+6} \mathrm{~kg} /$ year and $0.587 \times 10^{+6} \mathrm{~kg} /$ year for FOM and POM, respectively. Finally, the results showed that for an ITES, the payback period was 3.17 years and 3.84 years at partial and full operating modes, respectively. Furthermore after system life time (15 years) the saving operating costs were $1.735 \times 10^{5} \$$ and $0.899 \times 10^{5} \$$ for full and partial operating modes, respectively. As explained in section 5-5, table (5) and table (7), we concluded that for our case study, investment cost and payback period for FOM $\left(1.291 \times 10^{5} \$\right.$ and 3.84$)$ was bigger than that for POM $\left(1.148 \times 10^{5} \$\right.$ and 3.17$)$.

Although the payback period was shorter for POM but the amount of saving in operating cost during system life time (15 years) was higher for FOM $\left(1.735 \times 10^{5} \$\right)$ in comparison with that for POM $\left(0.899 \times 10^{5} \$\right)$.

From all above and as a final conclusion, when both ITES and convectional systems are available it is recommended to select ITES due to lower electricity consumption and operating cost. Then it is appropriate to select among FOM and POM, the mode with lower payback period. 


\section{References:}

ASHRAE, 2008. Chapter 39: cooling towers. In: ASHRAE Handbook HVAC Systems and Equipment. ASHRAE, Atlanta, GA, USA.

ASHRAE, 2009. Chapter 1: psychrometrics. In: ASHRAE Handbook Fundamentals. ASHRAE, Atlanta, GA, USA.

Bejan, A., Tsatsaronis, G., Moran, M., 1996. Thermal Design and Optimization. John Wiley \& Sons Inc, New York.

Bi, Y., Guo, T., Zhang, L., Chen, L., Sun, F., 2010. Entropy generation minimization for charging and discharging processes in a gas-hydrate cool storage system. Appl. Energ. $87,1149 \mathrm{e} 1157$.

Cengel, Y. A., \& Boles, M. A. 2011. Thermodynamics: an engineering approach (Vol. 5). New York: McGraw-Hill.

Cengel. Y. A., \& Cimbala, J. M. 2006. Fluid mechanics: fundamentals and applications. International Edition, McGraw Hill Publication, 185-201.

Chen, H.-J., Wangs, D.W.P., Chen, S.-L., 2005. Optimization of an ice-storage air conditioning system using dynamic programming method. Appl. Therm. Eng. 25, $461 \mathrm{e} 472$.

Dincer, I., 2002. On thermal energy storage systems and applications in buildings. Energ. Build. 34, 377e388.

Dincer, I., 2003. Refrigeration Systems and Application. John Wiley \& Sons Ltd., England.

GIP(Generation iran power) (2010). Transmission and Distribution Management Company (TAVANIR),“. Electric power industry in Iran. 
Habeebullah, B.A., 2007. Economic feasibility of thermal energy storage systems. Energ. Build. 39, 355e 363.

Henze, G.P., 2003. Parametric study of a simplified ice storage model under conventional and optimal control strategies. J.Sol. Energ. Eng. 125, 2e12 (ASME, New York).

Henze, G.P.,Biffar,B.,Kohn,D.,Becker,M.P., 2008.Optimaldesignand operation of a thermal storage systemfor a chilled water plant serving pharmaceutical buildings. Energ. Build. 40, 1004e1019.

Humpherys, K.K., Kattell, S., 1981. Basic Cost Engineering. Marcel Dekker, New York.

ICB (Iranian Central Bank), 2011. Available from: http://www.cbi.ir.

IPCC, 2007. Available from: http://www.ecocostsvalue.com/

IRIMO, 2006. Available from: http://www.irimo.ir/English/ statistics/synopH/bushehr.txt.

Kakac, S., Liu, H., 2002. Heat Exchangers: Selection, Rating and Thermal Design, second ed. CRC Press, Washington DC.

Kilkis, B., Kakac, S., 1989. Energy Storage System. In: Series E: Applied Sciences, vol. 167. Kluwer Academic Publishers. 703e720.

Kotas, T.J., 1995. The Exergy Method of Thermal Plant Analysis. Krieger Publishing Company, Florida.

MacPhee, D., Dincer, I., 2009. Performance assessment of some ice TES systems. Int. J. Therm. Sci. 48, $2288 \mathrm{e} 2299$.

MII (ministry of industries of Iran), 2011. Available from: http:// www.mim.gov.ir.

Oskounejad, M.M., 2006. Engineering Economy. Tehran Polytechnic. 
Panjeshahi, M.H., Ataei, A., 2008. Application of an environmentally optimum cooling water system design in water and energy conservation. Int. J. Environ. Sci. Tech. 5 (2), $251 \mathrm{e} 262$.

Rismanchi, B., et al. 2012. Energetic, economic and environmental benefits of utilizing the ice thermal storage systems for office building applications. Energy and Buildings $50,347-354$.

Rosen, M.A., Dincer, I., 2003. Exergy methods for assessing and comparing thermal storage systems. Int. J. Energy Res. 27, 415e430.

Roosen, P., Uhlenbruck, S., Lucas, K., 2003. Pareto optimization of combined cycle power system as a decision support tool for trading off investment vs. operating costs. Int. J. Therm. Sci. 42, 553e560.

Rosen, M.A., Dincer, I., Pedinelli, N., 2000. Thermodynamic performance of ice thermal energy storage systems. J. Energ. Resour. Tech. 122, $205 \mathrm{e} 211$.

Saito, A., 2002. Recent advances in research on cold thermal energy storage. Int. J. Refrigeration 25, 177e189.

Sanaye, S., Fardad, A., Mostakhdemi, M., 2011. Thermoeconomic optimization of an ice thermal storage system for gas turbine inlet cooling. Energy 36, 1057e1067.

Sanaye, S., \& Shirazi, A. 2012. Thermo-economic optimization of an ice thermal energy storage system for air-conditioning applications. Energy and Buildings, 60, 100-109.

Sanaye, S., \& Shirazi, A. 2013. Four E analysis and multi-objective optimization of an ice thermal energy storage for air-conditioning applications. International Journal of Refrigeration, 36(3), 828-841. 
Sayyaadi, H., Mehrabipour, R., 2012. Efficiency enhancement of a gas turbine cycle using an optimized tubular recuperative heat exchanger. Energy 38, 362e375.

Selbas, R., Kizilka, O., Sencan, A., 2006. Thermoeconomic optimization of subcooled and superheated vapor compression refrigeration cycle. Energy 31, $2108 \mathrm{e} 2128$.

Srinivasan, V., Shocker, A.D., 1973. Linear programming techniques for multidimensional analysis of preference. Psychometrika 38, 337e342.

UNEP, 2000. Global Environmental Outlook. United Nations, NY.

Wall, G., 1991. Optimization of refrigeration machinery. Int. J. Refrigeration 14, $336 \mathrm{e} 340$.

Wang, J., Zhai, Z., Jing, Y., Zhang, C., 2010. Particle swarm optimization for redundant building cooling heating and power system. Appl. Energy 87, 3668e3679.

West.j, J.E. Braun, 2004. Modeling partial charging and discharging of area constrain edice storage tank, HVAC \& Research 5 (July) 


\section{List of Figures:}

Fig1. The schematic diagram of the modeled ITES system for full operating mode (FOM)

Fig2. The schematic diagram of the modeled ITES system for partial operating mode $(\mathrm{POM})$

Fig3.Defination of full (1) and partial (2) ITES operating modes (dincer and rosen, 2003)

Fig4. Building cooling load profile, VCR load capacity for a conventional system as well as VCR load capacity for FOM and POM during a day.

Fig5. Variation of the maximum monthly values of ambient temperature during a year for city of Bushehr

Fig6. Pareto front curve for multi-objective optimization (The total annual cost versus total exergy effeciency) for ITES full operating mode

Fig7. Pareto front curve for multi-objective optimization (The total annual cost versus total exergy effeciency) for ITES partial operating mode Fig8.Non-dimensional Pareto optimal solutions and the final optimum point selected by using LINMAP decision-making method for FOM-ITES

Fig9. Non-dimensional Pareto optimal solutions and the final optimum point selected by using LINMAP decision-making method for POM-ITES

Fig10.Camparison between exergy destruction of various ITES equipment at the optimum selected ponit for FOM and POM

Fig11. The comparison of electricity consumptions of an optimum selected ITES for FOM and POM with that for conventional system during a year 


\section{Figures:}

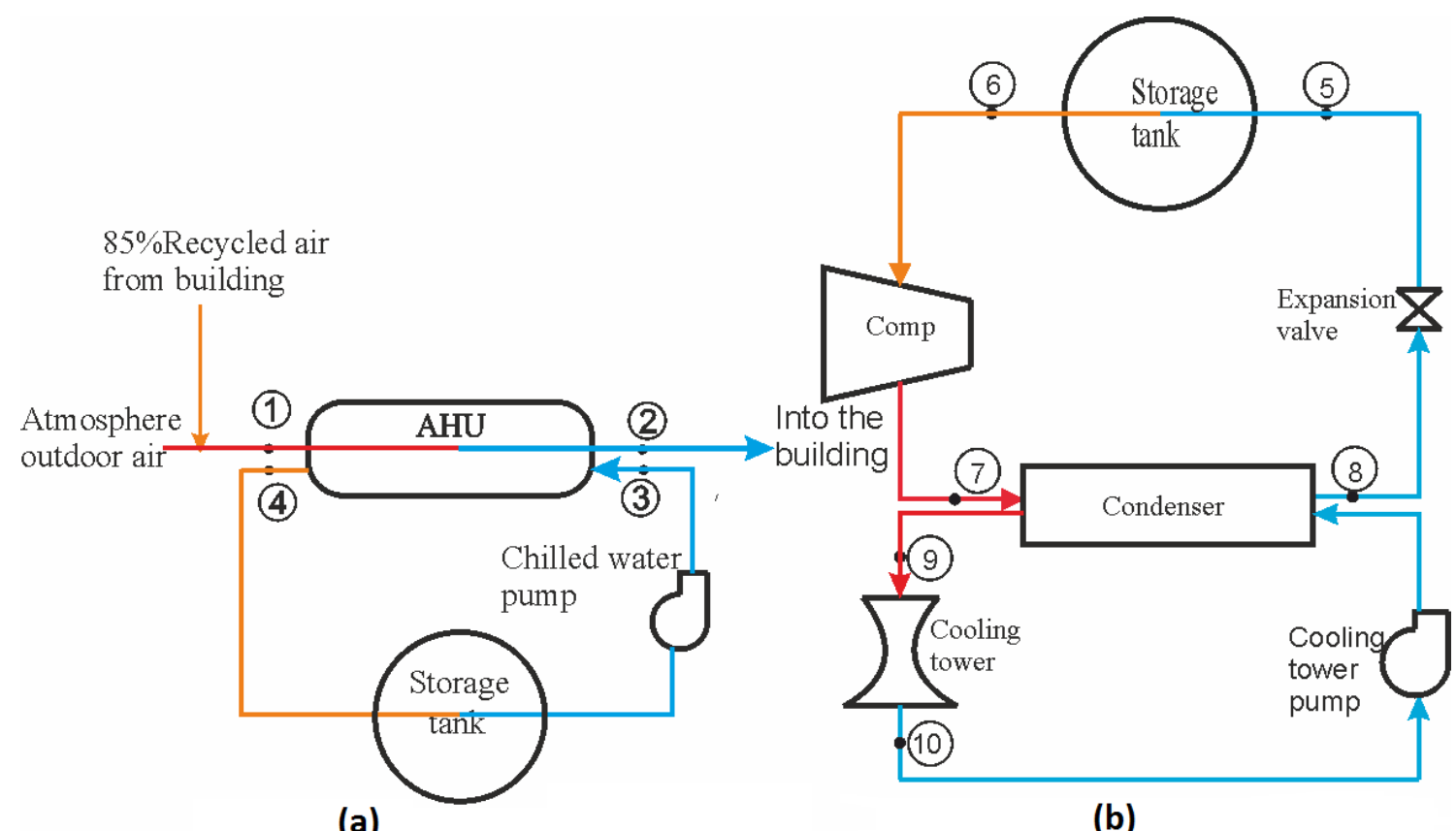

Fig1. The schematic diagram of the modeled ITES system for full operating mode (FOM)

(a) charging cycle (b) discharging cycle 


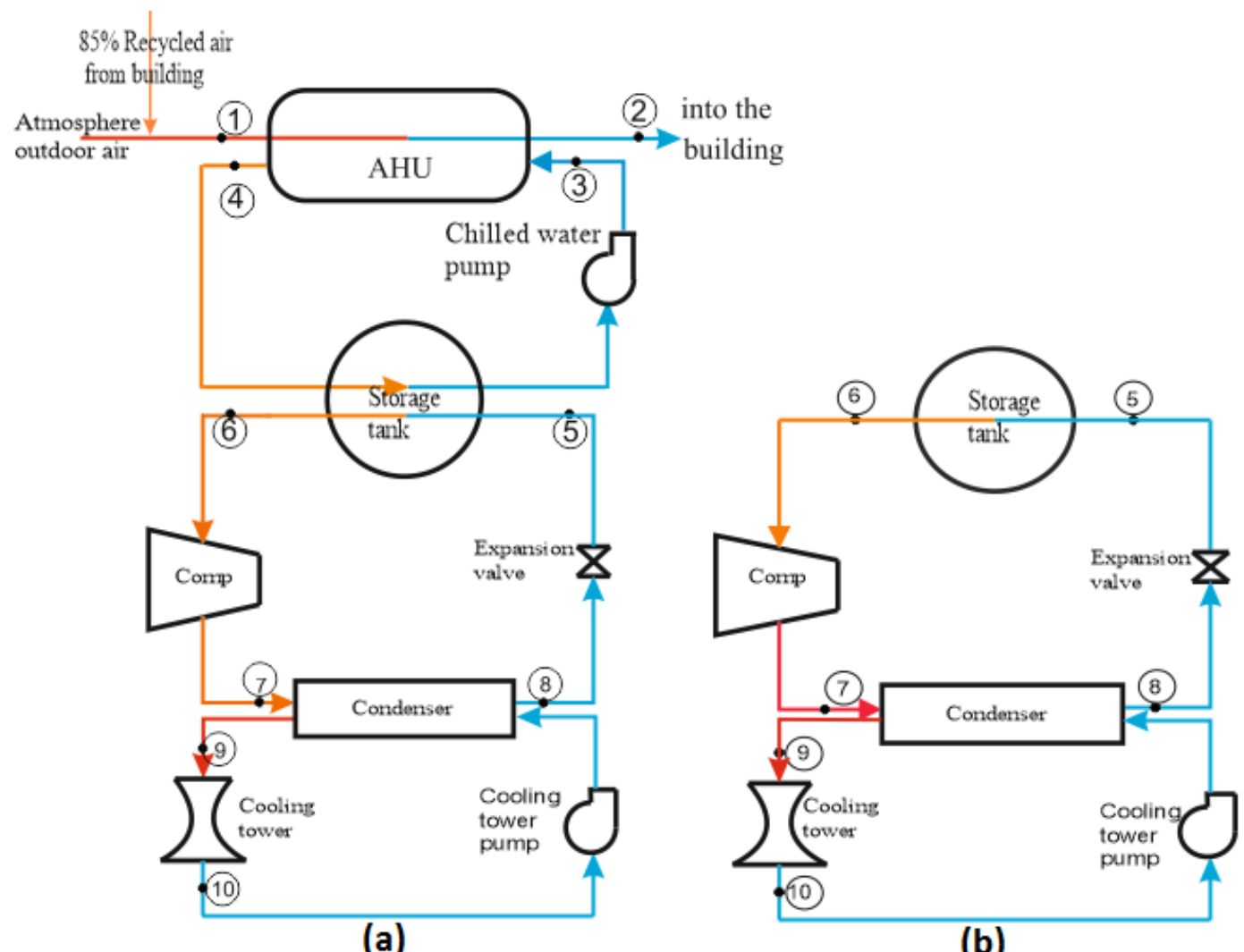

Fig2. The schematic diagram of the modeled ITES system for partial operating mode (POM) (a) charging cycle (b) discharging cycle

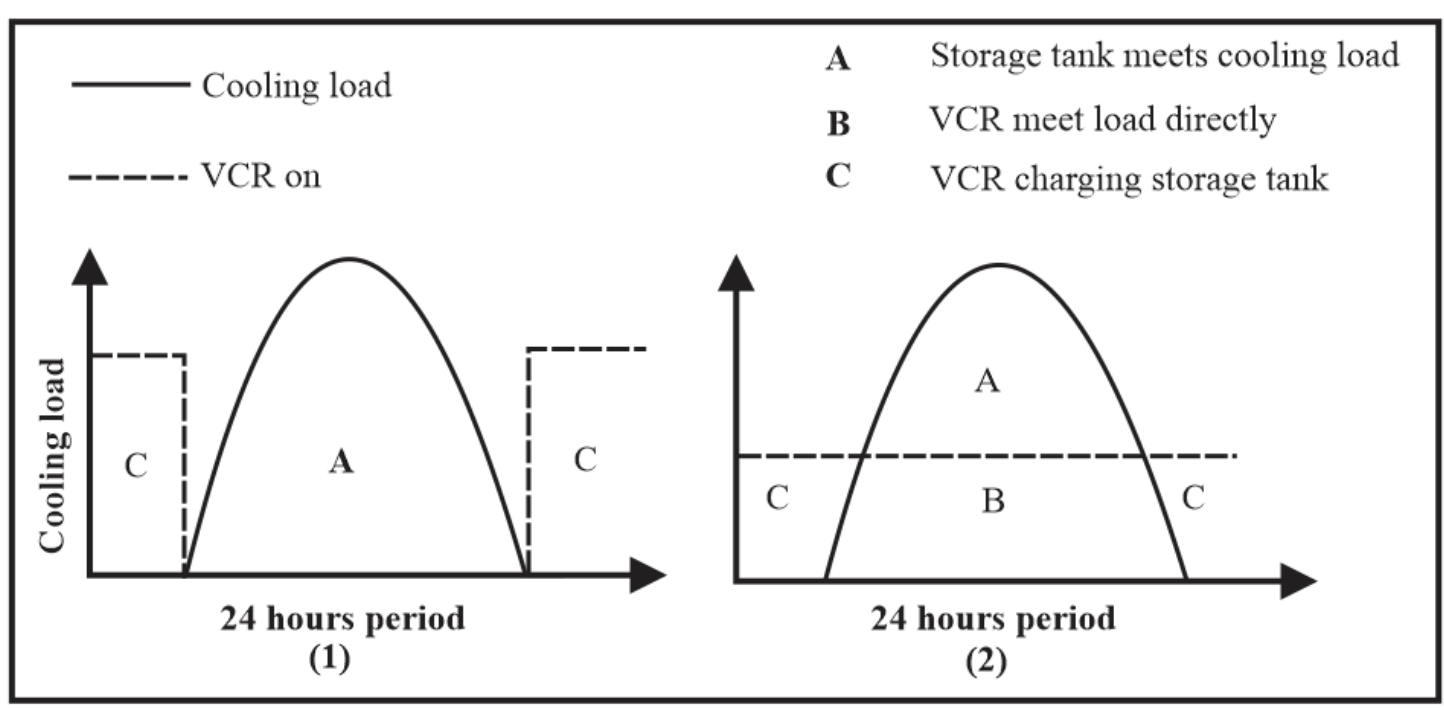

Fig3.Defination of full (1) and partial (2) ITES operating modes (Dincer and Rosen, 2003) 


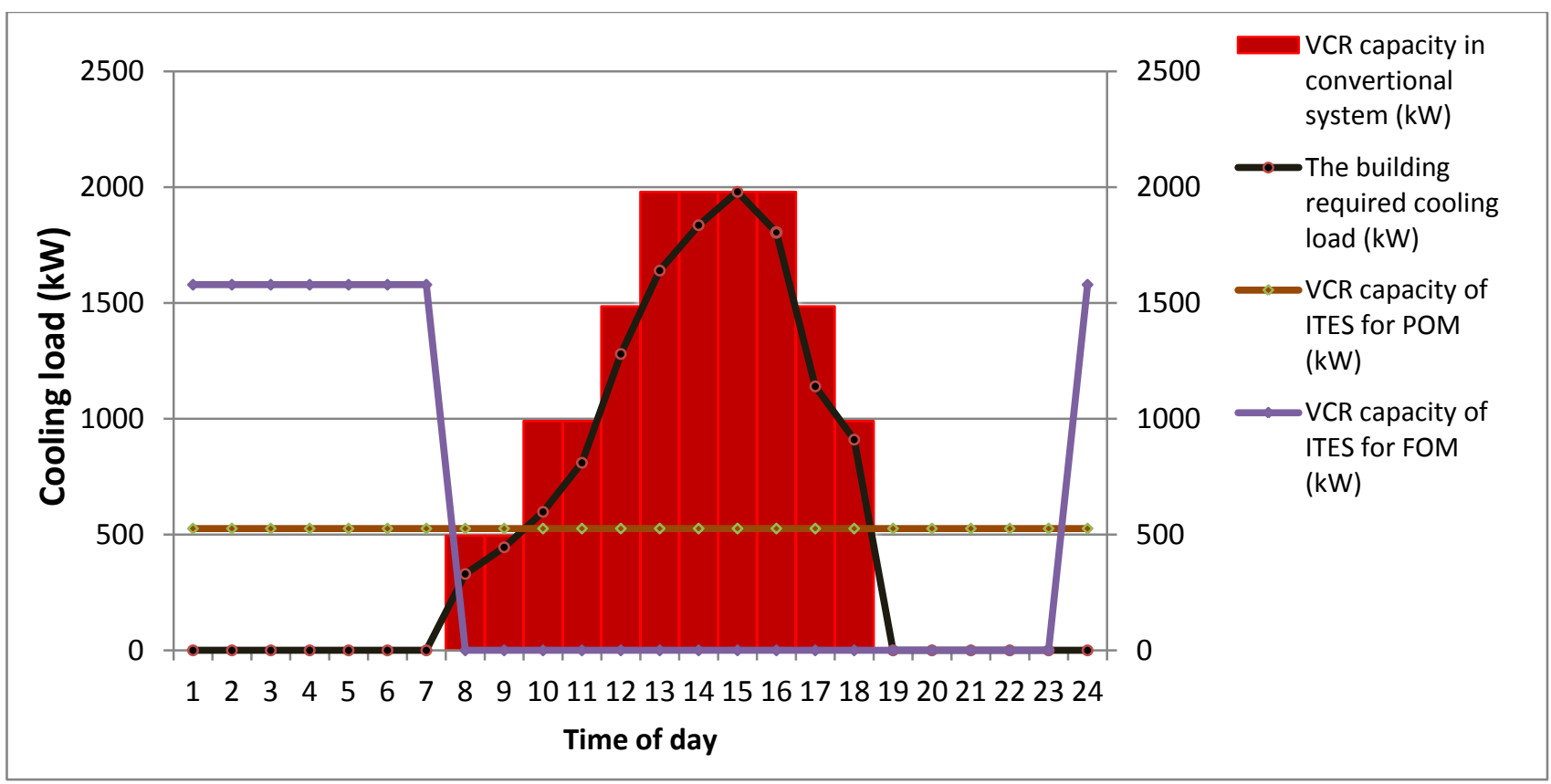

Fig4. Building cooling load profile, VCR load capacity for a conventional system as well as VCR load capacity for FOM and POM during a day.

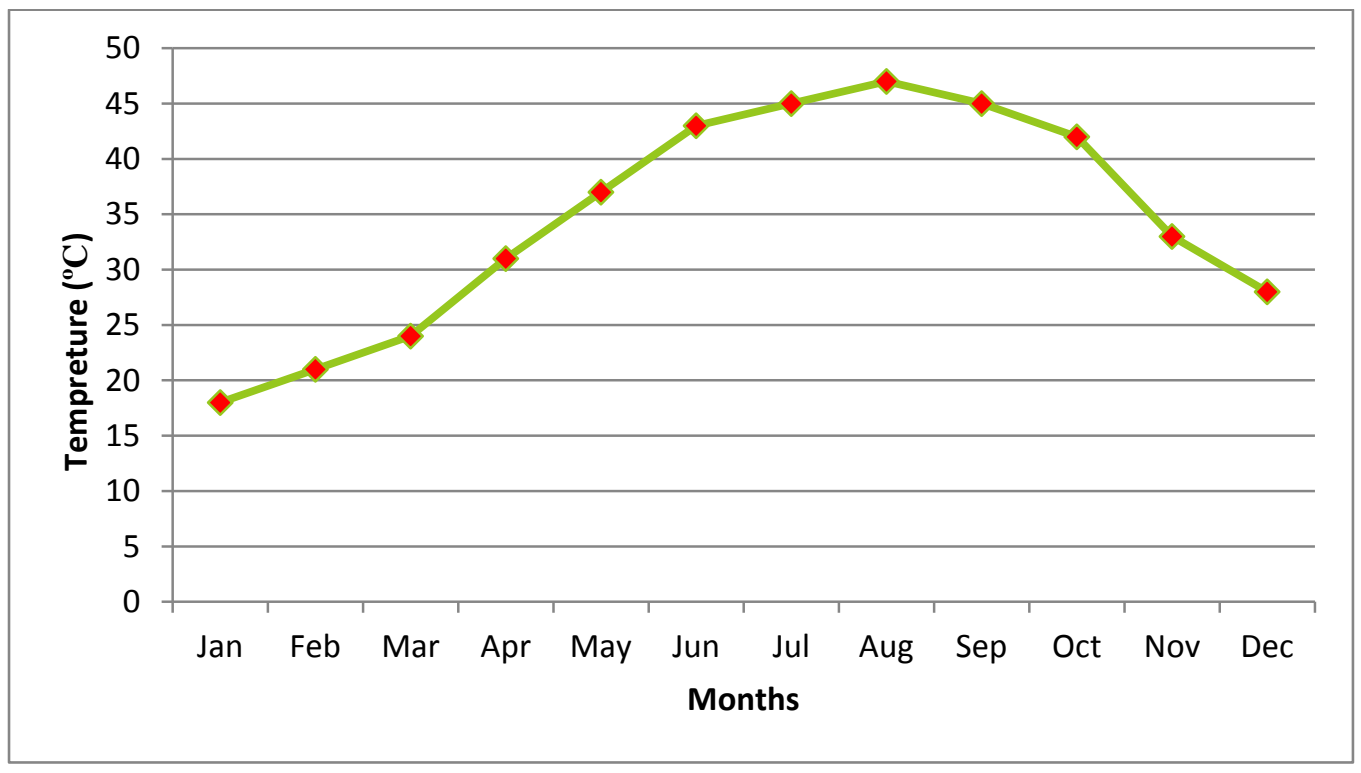

Fig5. Variation of the maximum monthly values of ambient temperature during a year for city of Bushehr 


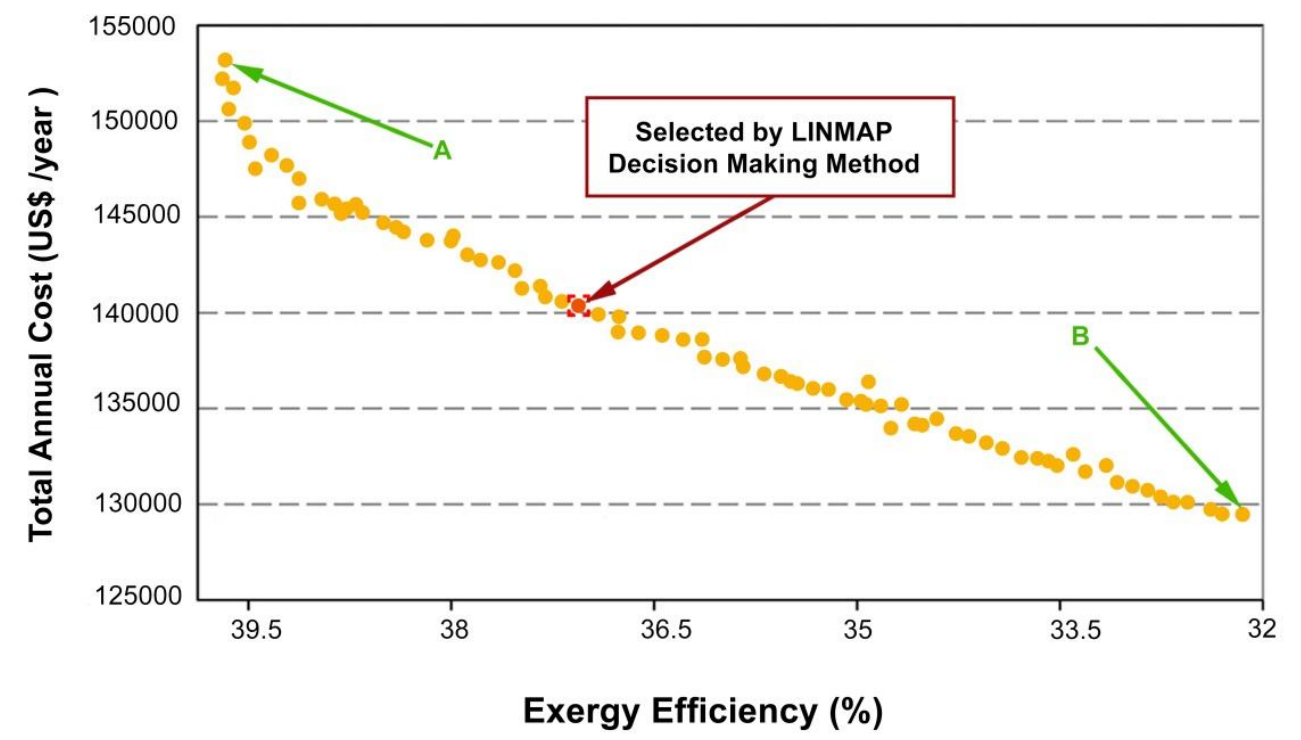

Fig6. Pareto front curve for multi-objective optimization (The total annual cost versus total exergy effeciency) for ITES full operating mode

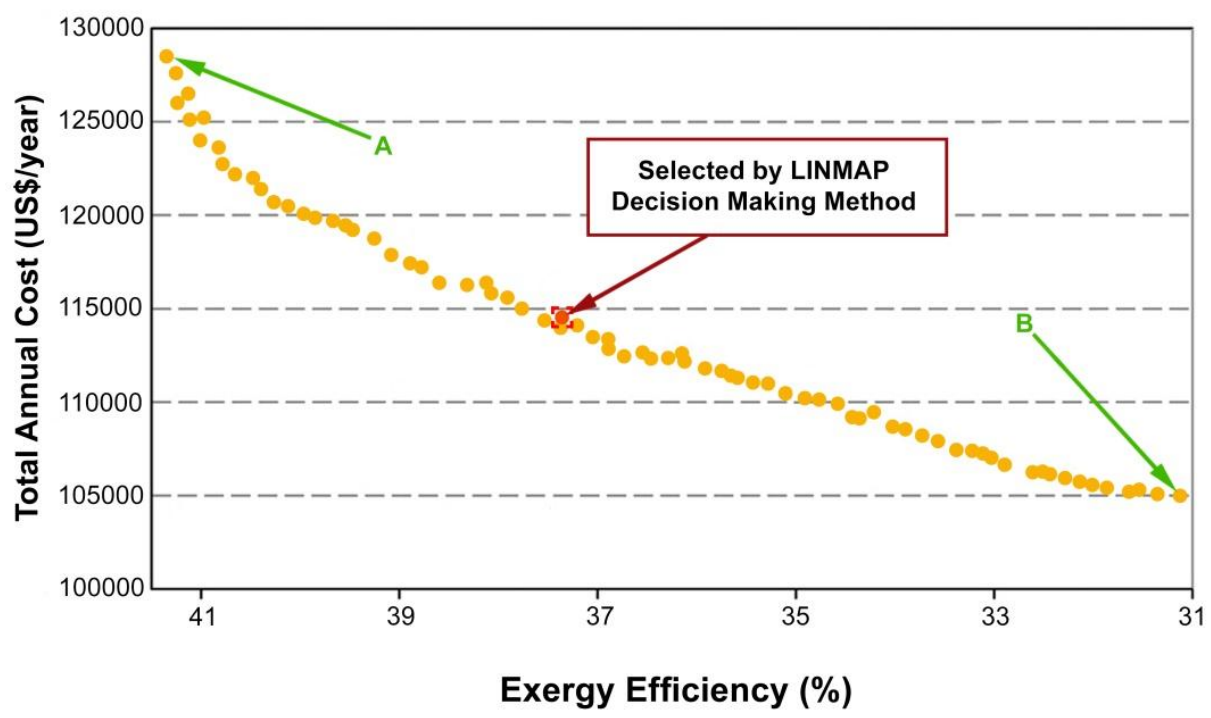

Fig7. Pareto front curve for multi-objective optimization (The total annual cost versus total exergy effeciency) for ITES partial operating mode 


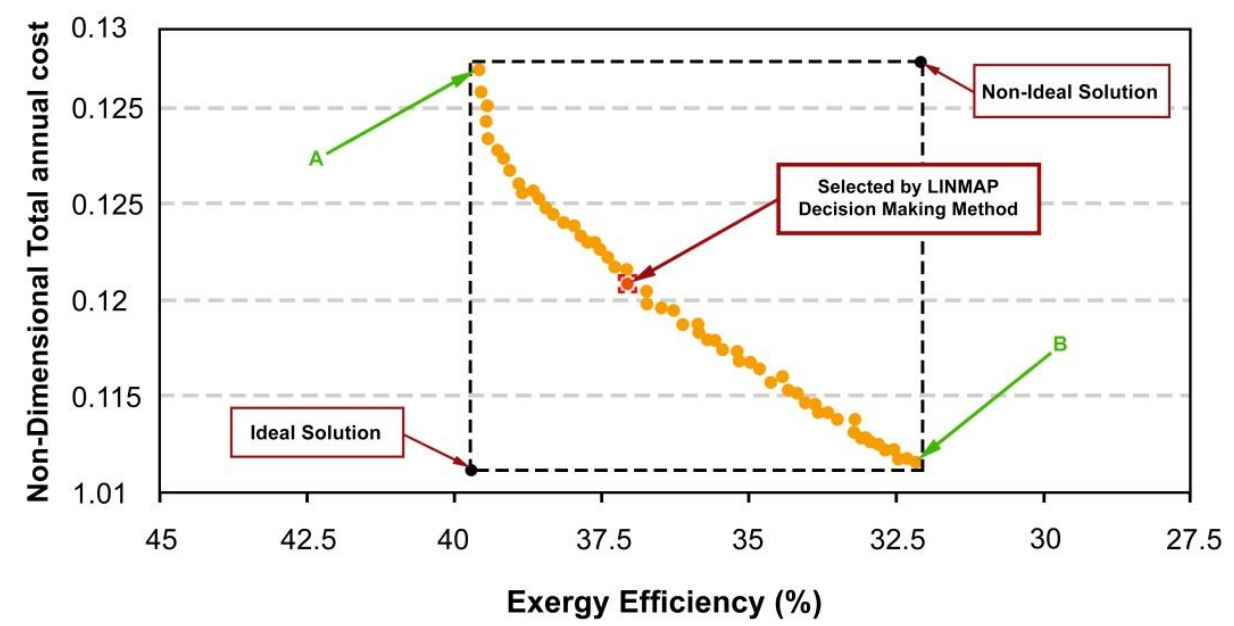

Fig8.Non-dimensional Pareto optimal solutions and the final optimum point selected by using LINMAP decision-making method for FOM-ITES

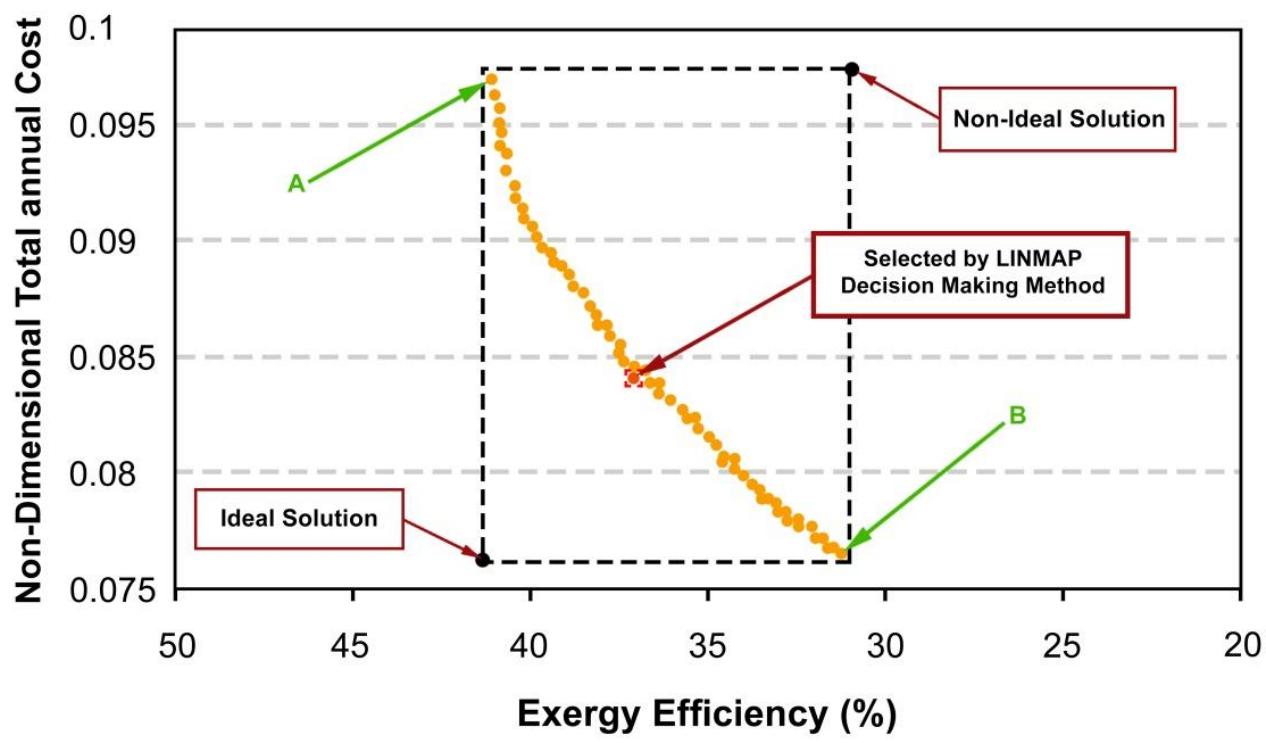

Fig9. Non-dimensional Pareto optimal solutions and the final optimum point selected by using LINMAP decision-making method for POM-ITES 


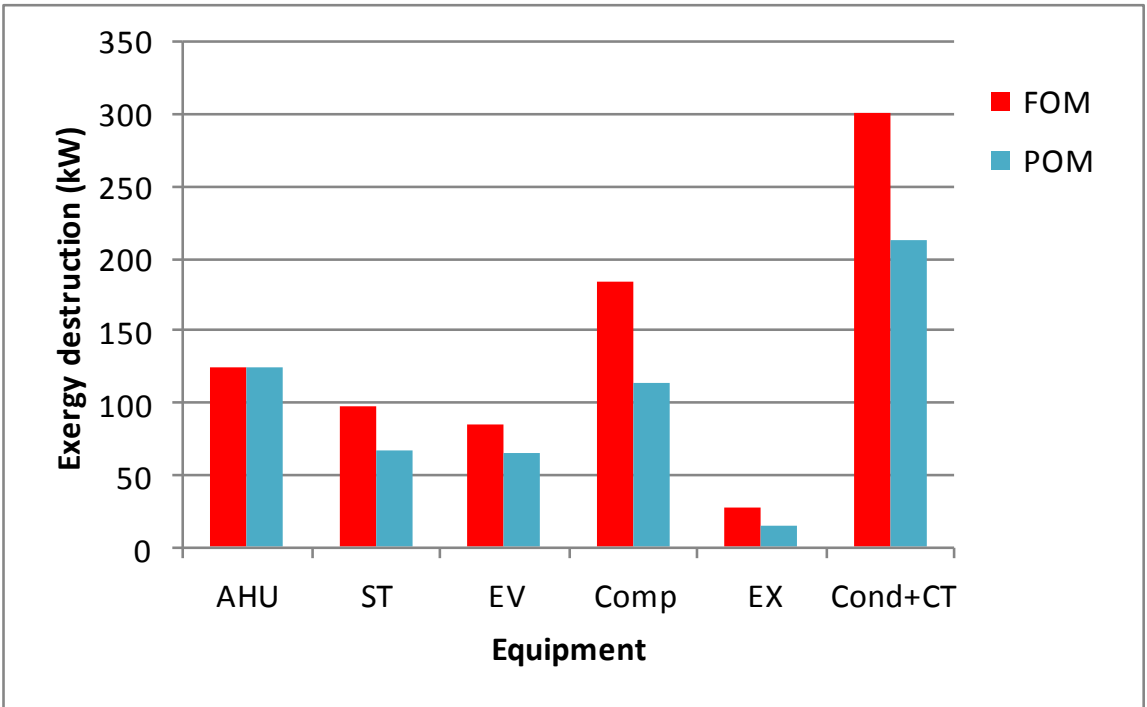

Fig10.Camparison between exergy destruction of various ITES equipment at the optimum selected ponit for FOM and POM

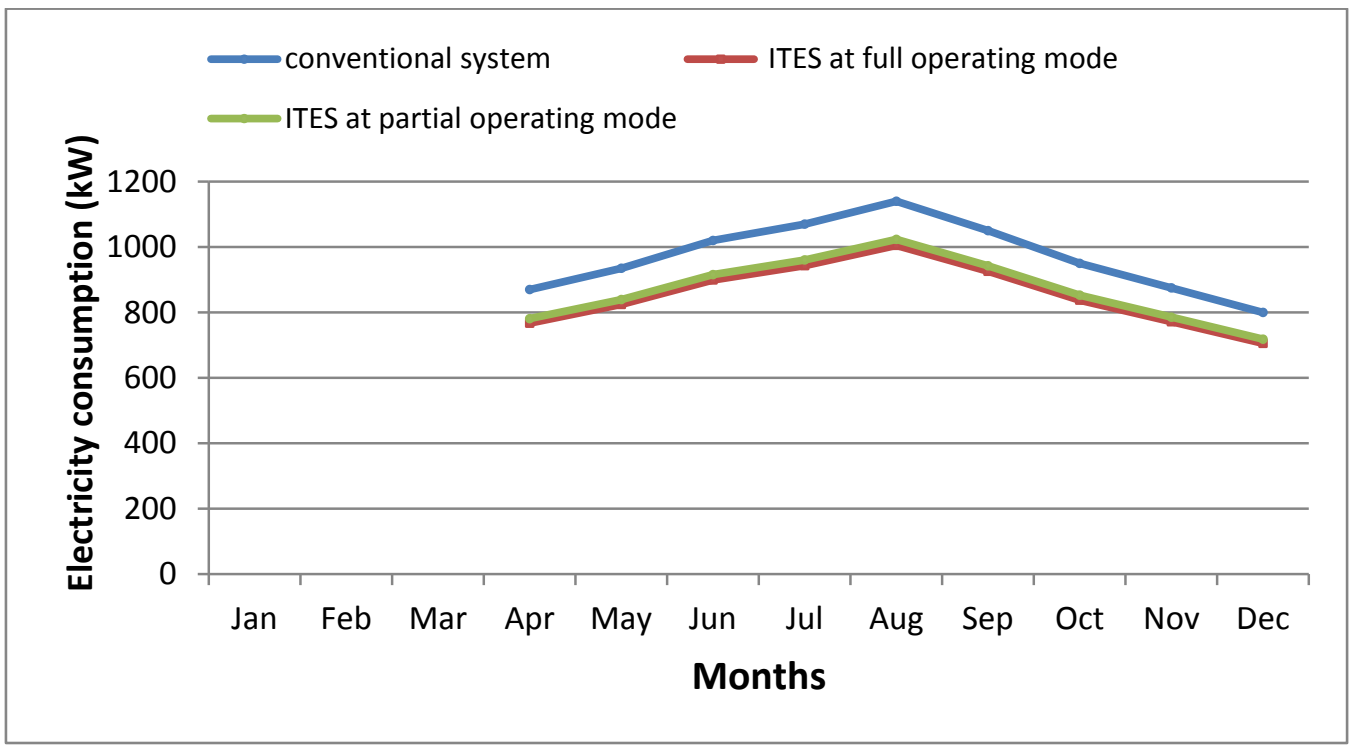

Fig11. The comparison of electricity consumptions of an optimum selected ITES for FOM and POM with that for conventional system during a year 


\section{List of tables:}

Table1- Cost functions of various equipment of ITES (Wall, 1991; Bejan et al., 1996; Roosen et al., 2003; Selbas et al., 2006; Habeebullah, 2007; Panjeshahi and Ataei, 2008) Table2-ITES system design parameters and their range of variation as well as system constraints

Table3-The building required cooling load, ITES provided cooling loads for FOM and POM as well as VCR load capacity of conventional system for our case study during 24 hours of a day

Table4- The comparison of computed values of system operating parameters including $\dot{m}_{r}$, the refrigerant mass flow rate, $\dot{W}_{\text {comp }}$, the compressor power consumption and COP, the coefficient of performance, obtained from modeling of vapor compression refrigeration (VCR) system with the corresponding values reported in Ref. (Dincer,2003) Table5-Optimum values of design parameters and objective functions obtained by multiobjective optimization and LINMAP decision making methods for FOM and POM Table6- The comparison of computed values of VCR system operating parameters for FOM and POM at the optimum point Table7-Investment cost of ITES system components at the optimum point for FOM and POM 


\section{Tables:}

Table1-Cost functions of various equipment of ITES (Wall, 1991; Bejan et al., 1996;

Roosen et al., 2003; Selbas et al., 2006; Habeebullah, 2007; Panjeshahi and Ataei, 2008)

\begin{tabular}{|c|c|}
\hline System equipment & Cost function \\
\hline Air handling unit(AHU) & $Z_{A H U}=24202 \times A_{A H U}^{0.4162}$ \\
\hline Pump & $Z_{\text {pump }}=705.48 \times \dot{W}_{\text {pump }}^{0.71}\left(1+\frac{0.2}{1-\eta_{\text {pump }}}\right)$ \\
\hline Ice storage tank & $Z_{S T}=8.67 \times 10^{\left[2.9211 \exp \left(0.1416 \log V_{S T}\right)\right]}$ \\
\hline Evaporator & $Z_{E V}=16648.3 \times A_{E V}^{0.6223}$ \\
\hline Compressor & $Z_{\text {comp }}=\frac{39.5 \dot{m}_{r}}{0.9-\eta_{\text {comp }}}\left(\frac{P_{d c}}{P_{\text {suc }}}\right) \operatorname{Ln}\left(\frac{P_{d c}}{P_{\text {suc }}}\right)$ \\
\hline Expansion value & $Z_{E X}=114.5 \times \dot{m}_{r}$ \\
\hline Condenser & $Z_{\text {cond }}=\left(516.62 \times A_{\text {cond }}\right)+268.45$ \\
\hline Cooling tower & $\begin{array}{l}Z=746.749 \times\left(m_{c T}\right)^{0.79}\left(\Delta T_{c T}\right)^{0.57}\left(T_{\text {in }, c T}-T_{\text {out }, c T}\right)^{-0.9924} \times \\
\left(0.022 T_{w b, \text { out }}+0.39\right)^{2.447}\end{array}$ \\
\hline Compression chiller & $Z_{\text {chiller }}=150.2 \times \dot{Q}_{\text {chiller }}$ \\
\hline
\end{tabular}


Table2-ITES system design parameters and their range of variation as well as system constraints

\begin{tabular}{|l|l|}
\hline Design parameters & Reason and definition \\
\hline $6<T_{\text {in, } A H U}<8$ & Typical data for refrigeration systems \\
\hline $11<T_{\text {out }, A H U}<13$ & Typical data for refrigeration systems \\
\hline$-10<T_{S T}<0$ & Typical data for refrigeration systems \\
\hline$-30<T_{E V}<0$ & The minimum and maximum refrigerant saturation \\
\hline$\left(T_{w b, \text { out }}\right)+5<T_{\text {cond }}<60$ & temperature in evaporator for a wide range of applications \\
\hline Constraints & temperature in condenser for a wide range of applications \\
\hline$T_{E V}<T_{S T}$ & Description \\
\hline$T_{F D, G l y c o l}<T_{S T}$ & For occurring heat transfer between evaporator and storage \\
& tank \\
\hline
\end{tabular}


Table3-The building required cooling load, ITES provided cooling loads for FOM and POM as well as VCR load capacity of conventional system for our case study during 24 hours of a day

\begin{tabular}{|c|c|c|c|c|c|c|}
\hline \multirow[t]{2}{*}{ Hour } & \multirow{2}{*}{$\begin{array}{l}\text { Building } \\
\text { cooling } \\
\text { load } \\
(\mathrm{kW})\end{array}$} & \multicolumn{2}{|c|}{ FOM } & \multicolumn{2}{|c|}{ POM } & \multirow{2}{*}{$\begin{array}{l}\text { VCR capacity } \\
\text { In } \\
\text { conventional } \\
\operatorname{system}(k W)\end{array}$} \\
\hline & & $\begin{array}{l}\text { Cooling load } \\
\text { provided by VCR for } \\
\text { charging storage } \\
\text { tank }(\mathrm{kW})\end{array}$ & $\begin{array}{l}\text { Cooling load } \\
\text { provided by } \\
\text { storage tank for } \\
\text { building } \\
\text { cooling }(\mathrm{kW})\end{array}$ & $\begin{array}{l}\text { Cooling load } \\
\text { provided by VCR for } \\
\text { charging storage } \\
\text { tank }(\mathrm{kW})\end{array}$ & $\begin{array}{l}\text { Cooling load } \\
\text { provided by } \\
\text { storage tank for } \\
\text { building } \\
\text { cooling }(\mathrm{kW})\end{array}$ & \\
\hline 1 & 0 & 1596.5 & 0 & 532.5 & 0 & 0 \\
\hline 2 & 0 & 1596.5 & 0 & 532.5 & 0 & 0 \\
\hline 3 & 0 & 1596.5 & 0 & 532.5 & 0 & 0 \\
\hline 4 & 0 & 1596.5 & 0 & 532.5 & 0 & 0 \\
\hline 5 & 0 & 1596.5 & 0 & 532.5 & 0 & 0 \\
\hline 6 & 0 & 1596.5 & 0 & 532.5 & 0 & 0 \\
\hline 7 & 0 & 1596.5 & 0 & 532.5 & 0 & 0 \\
\hline 8 & 330 & 0 & 330 & 532.5 & 0 & 495 \\
\hline 9 & 445 & 0 & 445 & 532.5 & 0 & 495 \\
\hline 10 & 598 & 0 & 598 & 532.5 & 65.5 & 990 \\
\hline 11 & 810 & 0 & 810 & 532.5 & 277.5 & 990 \\
\hline 12 & 1280 & 0 & 1280 & 532.5 & 747.5 & 1485 \\
\hline 13 & 1598 & 0 & 1598 & 532.5 & 1065.5 & 1980 \\
\hline 14 & 1776 & 0 & 1776 & 532.5 & 1243.5 & 1980 \\
\hline 15 & 1980 & 0 & 1980 & 532.5 & 1447.5 & 1980 \\
\hline 16 & 1795 & 0 & 1795 & 532.5 & 1262.5 & 1980 \\
\hline 17 & 1120 & 0 & 1120 & 532.5 & 587.5 & 1485 \\
\hline 18 & 910 & 0 & 910 & 532.5 & 377.5 & 990 \\
\hline 19 & 0 & 0 & 0 & 532.5 & 0 & 0 \\
\hline 20 & 0 & 0 & 0 & 532.5 & 0 & 0 \\
\hline 21 & 0 & 0 & 0 & 532.5 & 0 & 0 \\
\hline 22 & 0 & 0 & 0 & 532.5 & 0 & 0 \\
\hline 23 & 0 & 0 & 0 & 532.5 & 0 & 0 \\
\hline 24 & 0 & 1596.5 & 0 & 532.5 & 0 & 0 \\
\hline
\end{tabular}


Table4- The comparison of computed values of system operating parameters including $\dot{m}_{r}$, the refrigerant mass flow rate, $\dot{W}_{\text {comp }}$, the compressor power consumption and COP, the coefficient of performance, obtained from modeling of vapor compression refrigeration (VCR) system with the corresponding values reported in Ref. (Dincer,2003)

\begin{tabular}{|l|l|l|l|l|}
\hline $\begin{array}{l}\text { Input values of } \\
\text { parameters }\end{array}$ & $\begin{array}{l}\text { Output values } \\
\text { of parameters }\end{array}$ & $\begin{array}{l}\text { Reported } \\
\text { values of } \\
\text { parameters }\end{array}$ & Modeling results \\
\hline$T_{E V}\left({ }^{o} \mathrm{C}\right)$ & -20 & $\dot{m}_{r}(\mathrm{~kg} / \mathrm{s})$ & 0.2 & 0.2001 \\
\hline$T_{\text {cond }}\left({ }^{\circ} \mathrm{C}\right)$ & 40 & $\dot{W}_{\text {comp }}(\mathrm{kW})$ & 9 & 9.1043 \\
\hline$\dot{Q}_{E V}(k W)$ & 25.9 & $\mathrm{COP}$ & 2.87 & 2.8593 \\
\hline
\end{tabular}


Table5-Optimum values of design parameters and objective functions obtained by multiobjective optimization and LINMAP decision making methods for FOM and POM

\begin{tabular}{|l|l|l|}
\hline \multicolumn{1}{|c|}{$\begin{array}{c}\text { Design parameters and } \\
\text { objective functions }\end{array}$} & FOM & POM \\
\hline$T_{\text {in, AHU }}\left({ }^{o} \mathrm{C}\right)$ & 6.91 & 6.57 \\
\hline$T_{\text {out }, A H U}\left({ }^{\circ} \mathrm{C}\right)$ & 11.74 & 11.58 \\
\hline$T_{S T}\left({ }^{o} \mathrm{C}\right)$ & -3.11 & -3.94 \\
\hline$T_{E V}\left({ }^{o} \mathrm{C}\right)$ & -5.12 & -5.27 \\
\hline$T_{\text {cond }}\left({ }^{\circ} \mathrm{C}\right)$ & 38.46 & 37.73 \\
\hline Total annual cost $\left(\times 10^{5}\right.$ \$ / year $)$ & 1.291 & 1.051 \\
\hline System exergy efficiency (\%) & 36.71 & 37.19 \\
\hline
\end{tabular}


Table6- The comparison of computed values of VCR system operating parameters for FOM and POM at the optimum point

\begin{tabular}{|l|c|c|}
\hline \multicolumn{1}{|c|}{ System operating parameters } & FOM & POM \\
\hline$\dot{Q}_{E V P}(k W)$ & $1.596 \times 10^{3}$ & 532.5 \\
\hline$\dot{m}_{r}(k g / \mathrm{sec})$ & 11.15 & 3.72 \\
\hline$\dot{W}_{\text {Comp }}(k W)$ & 335.73 & 111.98 \\
\hline$\dot{Q}_{\text {Cond }}(k W)$ & $1.932 \times 10^{3}$ & 644.44 \\
\hline COP & & 4.7543 \\
\hline
\end{tabular}


Table7- Investment cost of ITES system components at the optimum point for FOM and

POM

\begin{tabular}{|l|l|l|}
\hline Equipment & Investment cost at the & Investment cost at the \\
& optimum selected & optimum selected \\
\hline AHU & system for FOM $\left(10^{5} \$\right)$ & system for POM $\left(10^{5} \$\right)$ \\
\hline ST & 0.2372 & 0.2372 \\
\hline EV & 0.2282 & 0.1992 \\
\hline Pump-Discharging & 0.1171 & 0.0638 \\
\hline CT Pump & 0.0329 & 0.0230 \\
\hline Cond+CT & 0.0344 & 0.0249 \\
\hline EX & 0.2653 & 0.1855 \\
\hline Comp & 0.007741 & 0.004421 \\
\hline
\end{tabular}

